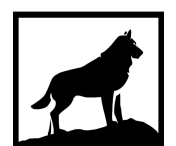

Michigan

Technological

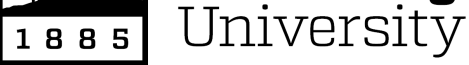

Michigan Technological University

Digital Commons @ Michigan Tech

2016

RESERVOIR ESTIMATION IN THE PENOBSCOT 3D SEISMIC VOLUME USING CONSTRAINED SPARSE SPIKE INVERSION, OFFSHORE NOVA SCOTIA, CANADA

Mengchu Xiao

Michigan Technological University, mengchux@mtu.edu

Copyright 2016 Mengchu Xiao

Recommended Citation

Xiao, Mengchu, "RESERVOIR ESTIMATION IN THE PENOBSCOT 3D SEISMIC VOLUME USING CONSTRAINED SPARSE SPIKE INVERSION, OFFSHORE NOVA SCOTIA, CANADA", Open Access Master's Thesis, Michigan Technological University, 2016.

https://doi.org/10.37099/mtu.dc.etdr/223

Follow this and additional works at: https://digitalcommons.mtu.edu/etdr

Part of the Geophysics and Seismology Commons 


\title{
RESERVOIR ESTIMATION IN THE PENOBSCOT 3D SEISMIC VOLUME USING CONSTRAINED SPARSE SPIKE INVERSION, OFFSHORE NOVA SCOTIA, CANADA
}

By

Mengchu Xiao

\begin{abstract}
A THESIS
Submitted in partial fulfillment of the requirements for the degree of MASTER OF SCIENCE

In Geophysics
\end{abstract}

MICHIGAN TECHNOLOGICAL UNIVERSITY

2016

(C) 2016 Mengchu Xiao 
This thesis has been approved in partial fulfillment of the requirements for the Degree of MASTER OF SCIENCE in Geophysics

Department of Geological and Mining Engineering and Sciences

Thesis Advisor:

Committee Member:

Committee Member:

Department Chair:
Wayne D. Pennington

Roger M. Turpening

Mir Sadri

John S. Gierke 


\section{Table of content}

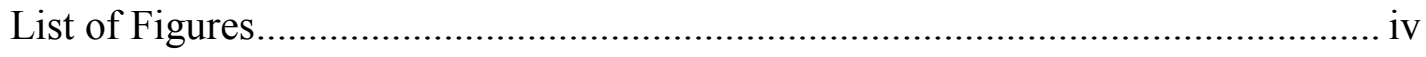

Acknowledgements ..................................................................................... vii

Abstract..................................................................................................... vii

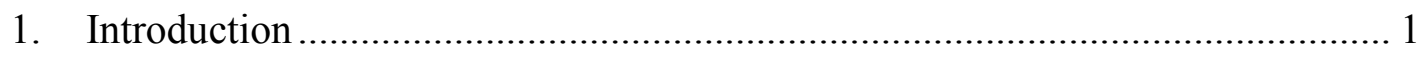

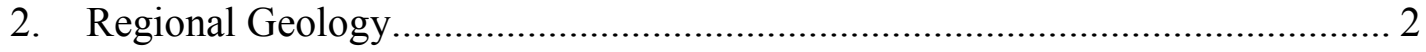

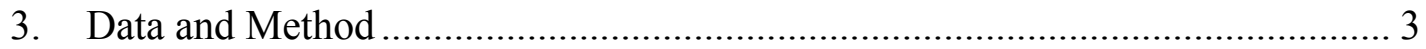

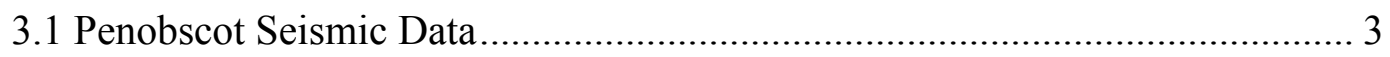

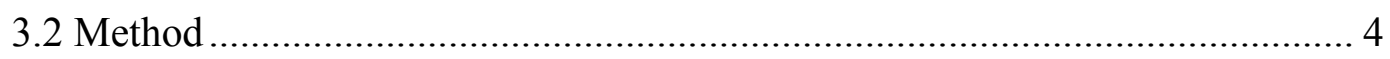

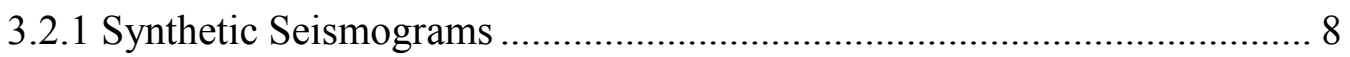

3.2.2 Wavelet Estimation and Seismic Well Tie.......................................... 11

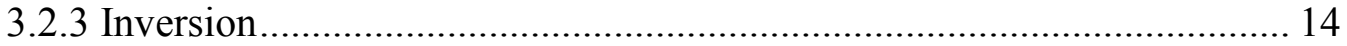

4. Seismic Results and Comparison with Log Data .......................................... 21

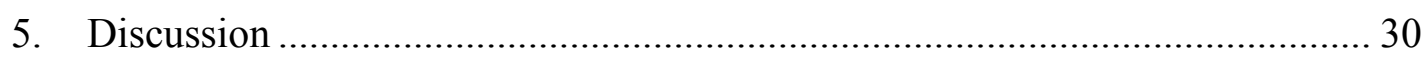

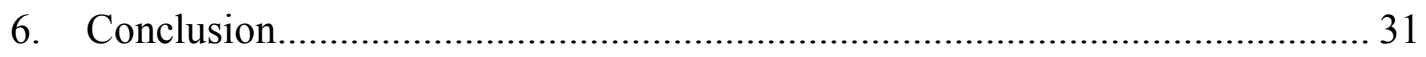

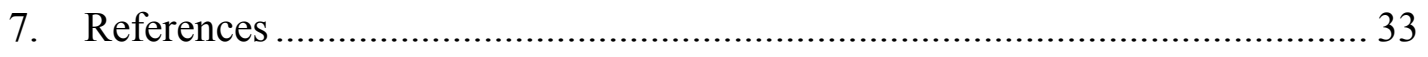

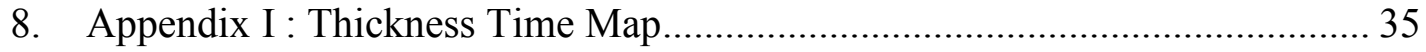




\section{List of Figures}

Figure 3.1. The base map of the Penobscot 3D seismic data, including two wells location 3

Figure 3.2. Inversion workflow for this research. 4

Figure 3.3. Section view of seismic data for inline 1079, three horizons tracked in this

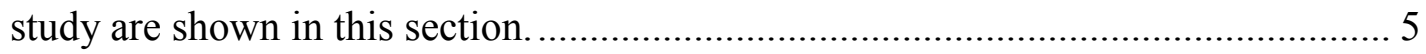

Figure 3.4. Tracked three horizons in section view.................................................. 6

Figure 3.5. Three horizons used in this study in map view...................................... 7

Figure 3.6. Synthetic seismogram of Well L-30 located in the inline 1177.............. 9

Figure 3.7. Synthetic seismogram of Well B-41 located in the inline 1329........... 10

Figure 3.8. Seismic welltie of Well L-30 located in the inline 1177....................... 12

Figure 3.9. Seismic welltie of Well B-41 located in the inline 1329...................... 13

Figure 3.10. Average wavelet after wavelet estimation of wells L-30 and B-41..... 14

Figure 3.11. Frequency range of Penobscot 3D seismic data................................... 15

Figure 3.12. Broadband model of Penobscot 3D seismic data in the arbitrary line,

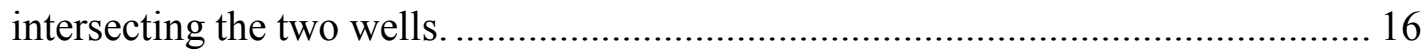

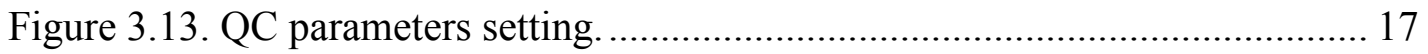

Figure 3.14. Initial inversion result of Penobscot 3D seismic data shown in the

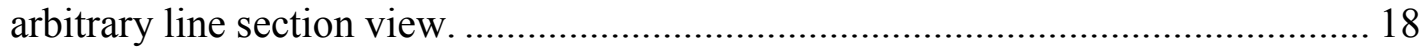

Figure 3.15. Initial inversion result of Penobscot 3D seismic data shown in 3D view. 18

Figure 3.16. Filters used in this research. 19 
Figure 3.17. (a) Low frequency model after using low pass filter. (b) Initial inversion result after using bandpass filter. (c) Final inversion result after merging (a) and (b).

Figure 4.1. (a) GR logs are shown on final inversion result in section view cross the two wells. (b) GR log for the well B-41 shown on final inversion result. (c) GR log for the well L-30 shown on final inversion result. 22

Figure 4.2. Low GR and SP values indicate a sand layer. (a) GR, SP, Neutron Porosity, and impedance curves for the well L-30. (b) GR, SP, Neutron Porosity, and impedance curves for the well B-41.

Figure 4.3. The thickness map (depth unit) of different impedance ranges, the lower limit of impedance is $7.9 \times 10^{6} \mathrm{~kg} / \mathrm{m}^{3 *} \mathrm{~m} / \mathrm{s}$, but the upper limit numbers are different: (a) $8.2 \times 10^{6} \mathrm{~kg} / \mathrm{m}^{3 *} \mathrm{~m} / \mathrm{s}$ (b) $8.4 \times 10^{6} \mathrm{~kg} / \mathrm{m}^{3 *} \mathrm{~m} / \mathrm{s}$ (c) $8.6 \times 10^{6} \mathrm{~kg} / \mathrm{m}^{3 *} \mathrm{~m} / \mathrm{s} \mathrm{(d)} 8.8 \times 10^{6}$ $\mathrm{kg} / \mathrm{m}^{3 *} \mathrm{~m} / \mathrm{s}$ (e) $9.0 \times 10^{6} \mathrm{~kg} / \mathrm{m}^{3 *} \mathrm{~m} / \mathrm{s}$. These five maps are use one color scale.......... 25 Figure 4.4. The relationship between impedance and porosity ................................ 26

Figure 4.5. Porosity of the target sand layer in section view, showing the arbitrarily line cross two wells section. 26

Figure 4.6. Porosity of the target sand layer in 3D view........................................ 27

Figure 4.7. The porosity of the middle of the layer is shown in map view. 27

Figure 4.8. The pore thickness map in meters. The lower limit of impedance is $7.9 \times 10^{6} \mathrm{~kg} / \mathrm{m}^{3 *} \mathrm{~m} / \mathrm{s}$, but the upper limit numbers are different: (a) $8.2 \times 10^{6} \mathrm{~kg} / \mathrm{m}^{3 *} \mathrm{~m} / \mathrm{s}$ (b) $8.4 \times 10^{6} \mathrm{~kg} / \mathrm{m}^{3 *} \mathrm{~m} / \mathrm{s}$ (c) $8.6 \times 10^{6} \mathrm{~kg} / \mathrm{m}^{3 *} \mathrm{~m} / \mathrm{s}$ (d) $8.8 \times 10^{6} \mathrm{~kg} / \mathrm{m}^{3 *} \mathrm{~m} / \mathrm{s}$ (e) $9.0 \times 10^{6}$ $\mathrm{kg} / \mathrm{m}^{3 *} \mathrm{~m} / \mathrm{s}$. These five maps are use one color scale. 
Figure 8.1. The thickness map (TWT unit) of impedance between $7.9 \times 10^{6} \mathrm{~kg} / \mathrm{m}^{3 *} \mathrm{~m} / \mathrm{s}$ to $8.2 \times 10^{6} \mathrm{~kg} / \mathrm{m}^{3 *} \mathrm{~m} / \mathrm{s}$. 35

Figure 8.2. The thickness map (TWT unit) of impedance between $7.9 \times 10^{6} \mathrm{~kg} / \mathrm{m}^{3 *} \mathrm{~m} / \mathrm{s}$ to $8.4 \times 10^{6} \mathrm{~kg} / \mathrm{m}^{3 *} \mathrm{~m} / \mathrm{s}$ 36

Figure 8.3. The thickness map (TWT unit) of impedance between $7.9 \times 10^{6} \mathrm{~kg} / \mathrm{m}^{3 *} \mathrm{~m} / \mathrm{s}$ to $8.6 \times 10^{6} \mathrm{~kg} / \mathrm{m}^{3 *} \mathrm{~m} / \mathrm{s}$. 36 Figure 8.4. The thickness map (TWT unit) of impedance between $7.9 \times 10^{6} \mathrm{~kg} / \mathrm{m}^{3 *} \mathrm{~m} / \mathrm{s}$ to $8.8 \times 10^{6} \mathrm{~kg} / \mathrm{m}^{3 *} \mathrm{~m} / \mathrm{s}$. 37

Figure 8.5. The thickness map (TWT unit) of impedance between $7.9 \times 10^{6} \mathrm{~kg} / \mathrm{m}^{3 *} \mathrm{~m} / \mathrm{s}$ to $9.0 \times 10^{6} \mathrm{~kg} / \mathrm{m}^{3 *} \mathrm{~m} / \mathrm{s}$. 37 


\section{Acknowledgements}

First, I would like to express my gratitude to my advisor Dr. Pennington for his guidance during my research work. Dr. Pennington encouraged me all the time, and gave me some suggestions as to how I can not only improve my research skills, but acquire knowledge about interpreting seismic data. In addition, I would like to thank my committee members, Professor Mir Sadri and Professor Turpening, for their helpful comments on my thesis.

It is a great chance to thank all my friends for always being there for me. I would like to thank all my peers in the Spot Lab who were always willing to help when needed.

Next, my thanks to the dGB Earth Sciences, and the OpendTect Company, who provide free access to the 3D Penobscot seismic data online. Thanks to Google Earth, which is used to show the location of the Penobscot study area. At the same time, I would like to give thanks to CGG and Schlumberger; I used Jason Geoscience Workbench, provided by CGG, and Petrel, provided by Schlumberger, in this research.

Finally, I would like to thank my parents and my grandmother for their support and encouragement, they always gave me power when I met difficulties. I am a lucky girl who grew up surrounded by their love. 


\section{Abstract}

The Penobscot study area is located offshore Nova Scotia, Canada. There are two wells, which penetrate the highest potentially commercial bodies in the Abenaki Formation. In order to investigate the potential for locating additional hydrocarbon reservoirs, well log data was used and the Penobscot 3D seismic dataset was analyzed using Constrained Sparse Spike Inversion. From the well log data, low GR and SP values are an indication of a permeable sand layer, which provides the target zone in this study. Impedance - porosity crossplots gave the relationship between impedance and porosity, where a low impedance sand layer is correlated with high porosity. It was found that the target sand layer has low impedance, a feature recognizable from the inversion results. The porosity of the whole sand layer calculated by the linear function from the relationship between impedance and porosity. The calculation of thickness of this sand layer from maps representing different impedance intervals provided numeric evidence to show there is a low impedance sand layer in the well L-30. The pore thickness map results indicate there is greater pore thickness in well L-30 than B-41. It appears that the company drilled at the optimal location for the initial (L-30) well, and tested the extent of potential reservoir rock with the second (B-41) well. The potential reservoir is apparently fairly small, and restricted to the area around L-30. There may or may not be value in testing another location across a fault, but the rock behind the fault is likely not as high quality as at L-30 and the highquality regions are small in size and not connected. 


\section{Introduction}

Seismic inversion is a useful tool for exploration and development companies to investigate potential hydrocarbon reservoir characteristics. There are different types of inversions algorithms used, but all, when carried to interpretation, make a transformation from seismic to geological information based on different calculation methods, well log data, and seismic data (Veeken, \& Silva, 2004). For this study, the Penobscot 3D seismic data set has sufficiently good quality to be used for such an investigation. This data set covers an area of $86.616 \mathrm{~km}^{2}$, offshore of Nova Scotia, Canada, including the sites of two wells. Using the seismic data, and well log data, the Constrained Sparse Spike Inversion (CSSI) was used. CSSI makes use of well logs and seismic data to invert poststack seismic data into an acoustic impedance cube, on which an interpretation of geological properties can be based.

This data set has already been studied by the Canada Nova Scotia Offshore Petroleum Board (CNSOPB) and the Geological Survey of Canada (GSC). Penobscot 3D seismic data is public domain data, and some other investigators have already performed different types of inversion on it. Ahmad (2013) used Recursive Inversion to interpret Penobscot 3D seismic data, with an impedance - porosity crossplot to get some information about the lithology, and separate sand points from non-reservoir by gamma ray values in the crossplot. In Sayers paper (2013), the Spectral Inversion method improved vertical resolution, and increased the resolution of bed thickness. In the present paper, the inversion method used is CSSI. This paper presents the low impedance target sand layer quality, using the calculation of the thickness, porosity 
and pore thickness of the sand layer and crossplots to compare properties of the whole sand layer. The purpose of this study was to predict the properties of the whole target layer, and find good locations for additional well locations.

\section{Regional Geology}

The Penobscot study area is located in the Scotian Basin, north of Sable Island, offshore of Nova Scotia. The Scotian Basin covers 300,000 $\mathrm{km}^{2}$ along the Nova Scotia margin. It is subdivided into four sub-basins: Laurentian, Abenaki, Sable, and Shelburne (Campbell, et al., 2015). The geological history of the Scotian Basin started in the Middle Triassic Period. When the North American plate separated from the African plate, after the break-up of Pangaea, it created interconnected rift basins, including the Scotian Basin. During the Late Jurassic Period the Abenaki Formation was deposited in the southwestern part of the Scotian Basin (Kidston, et al., 2005). The Abenaki Formation is the formation being studied here, which is identified on the stratigraphic column in Figure 2.1. The Abenaki Formation was deposited during the spreading of the sea floor. In 1976, PetroCanada-Shell drilled two wells, L-30 and B-41 into the Abenaki Formation. These wells penetrated the formation's Misaine and Baccaro members. 


\section{Data and Method}

\subsection{Penobscot Seismic Data}

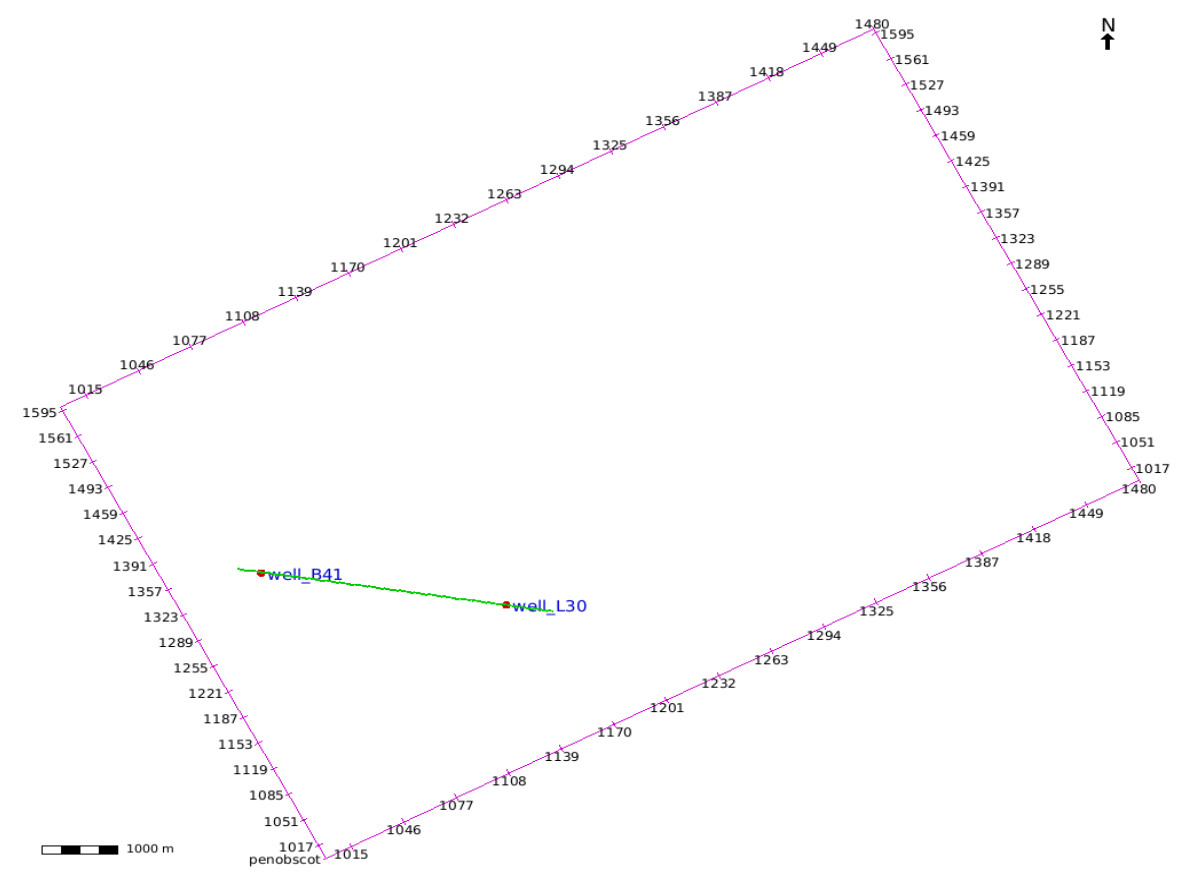

Figure 3.1. The base map of the Penobscot 3D seismic data, including two wells location. The green arbitrary line cross over well L-30 and B-41.

The data used in this project were the Penobscot 3D post-stack seismic data. It includes a 3D seismic survey, and logs from the two wells, B-41 and L-30, drilled in 1976 by PetroCanada-Shell. The 3D survey is nominally $7.2 \mathrm{~km}$ by $12.03 \mathrm{~km}$, covering an area of $86.6 \mathrm{~km}^{2}$. The total study area map is shown in Figure 3.1. The study area includes the Inline Ranges 1000 to 1600 , Crossline Ranges 1000 to 1481 , and $\mathrm{Z}$ ranges 0 to $6000 \mathrm{~ms}$ with the sample rate at $4 \mathrm{~ms}$. The well $\log$ data includes density, sonic, gamma ray, spontaneous potential, neutron porosity, and resistivity logs. 


\subsection{Method}

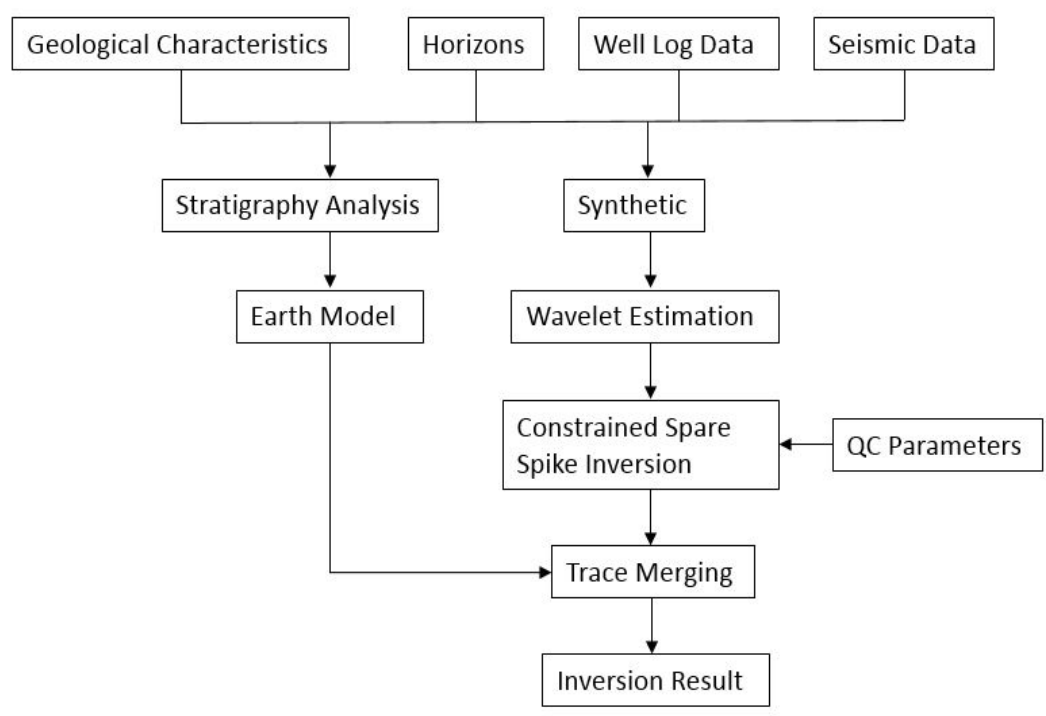

Figure 3.2. Inversion workflow for this research.

Acoustic impedance is one of several rock properties. The use of inversion methods provides the interpreter with rock properties instead of reflection character. This allows for details of the data's geological information to be inferred. This study uses a recursive inversion method, based on sparse impulse deconvolution (Wang \& $\mathrm{Lu}$, 2011). Applied to Penobscot 3D seismic data, it includes three main processes: first, calculate reflection coefficients to get a synthetic seismogram, secondly, work out the broad band impedance model constrained by well log data, and the low frequency model will be exported after using a low pass filter, last, the absolute impedance inversion result is produced after merging the low frequency model and the bandpass inversion model. This method creates an acoustic impedance cube, which describes the acoustic impedance of the rocks. This method allows for the recovery of low frequency information. It transforms seismic data to a pseudo-acoustic impedance log at every trace. The workflow chart of this method is shown in Figure 3.2. Figure 3.3 
shows three horizons tracked in this study, tracked horizons cross well L-30 and B41 shown in section view (Figure 3.4) and map view (Figure 3.5), which are used to help guide the inversion.

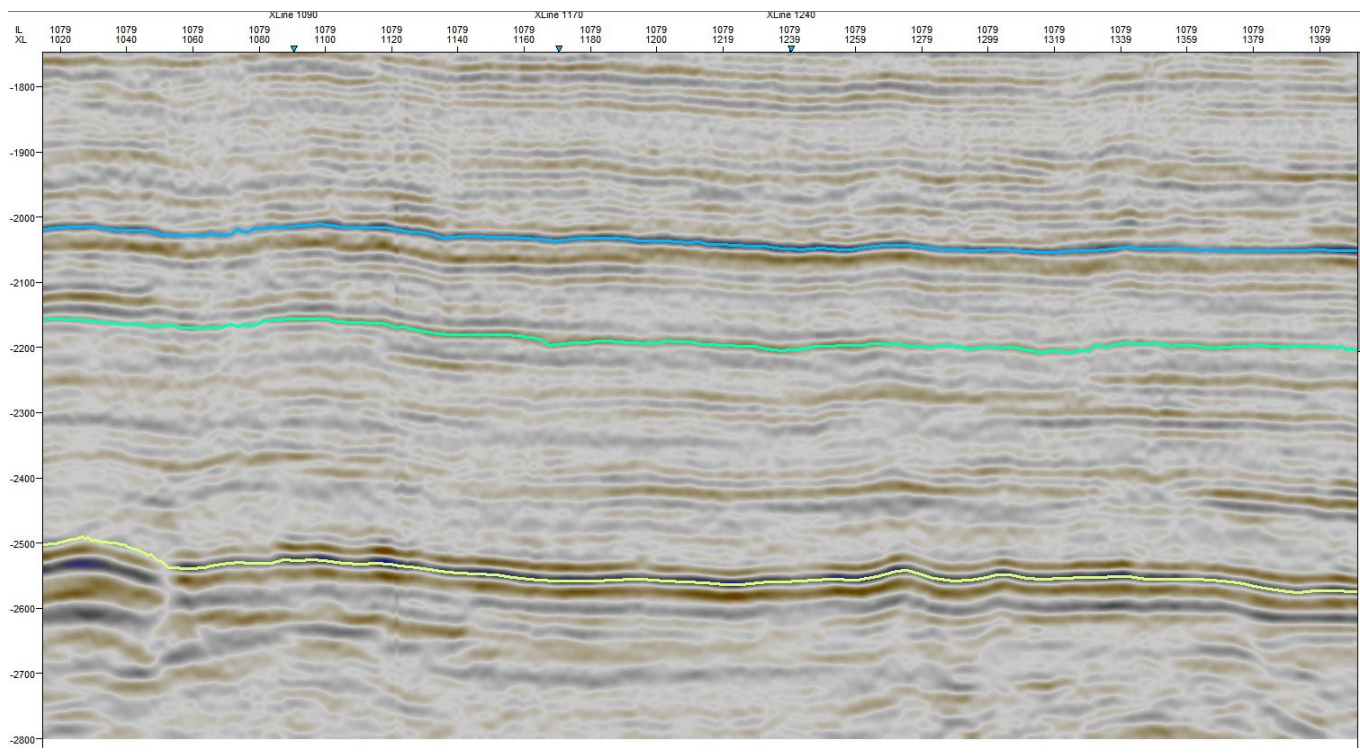

Figure 3.3. Section view of seismic data for inline 1079, three horizons tracked in this study are shown in this section. The blue line is Horizon 1, the green one is Horizon 2, the yellow line stands for Horizon 3. 


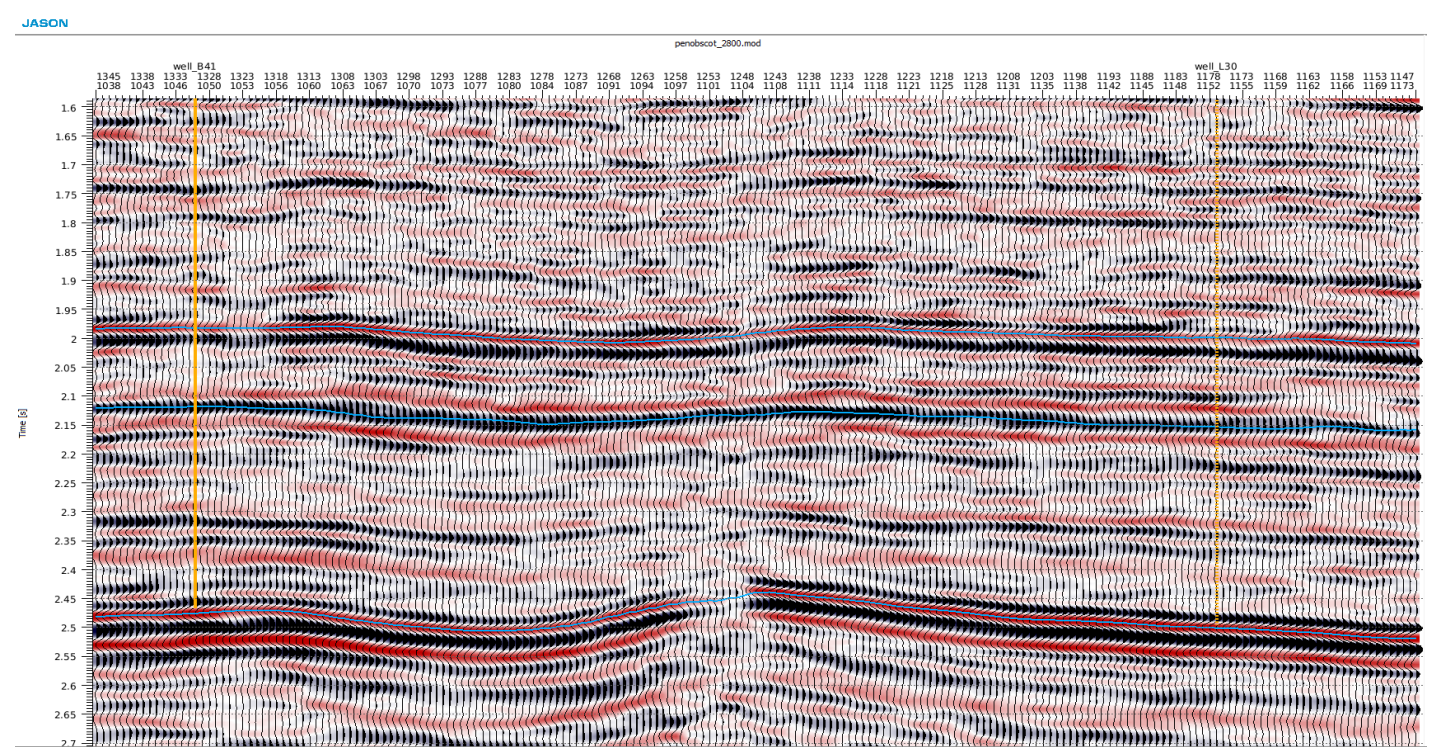

Figure 3.4. Tracked three horizons, this is the section view connecting well L-30 and B-41. Two orange lines identify well locations. Three blue lines present three horizons used in the study. Original Seismic traces are shown on this section.

From the inversion results, some porosities of the study area will be analyzed, by calculating porosity of the whole sand layer from the crossplot, which show the relationship between acoustic impedance and porosity as a linear function, and calculate out the thickness and pore thickness of a whole sand layer. Results that provide details will be presented in the following paragraphs. 


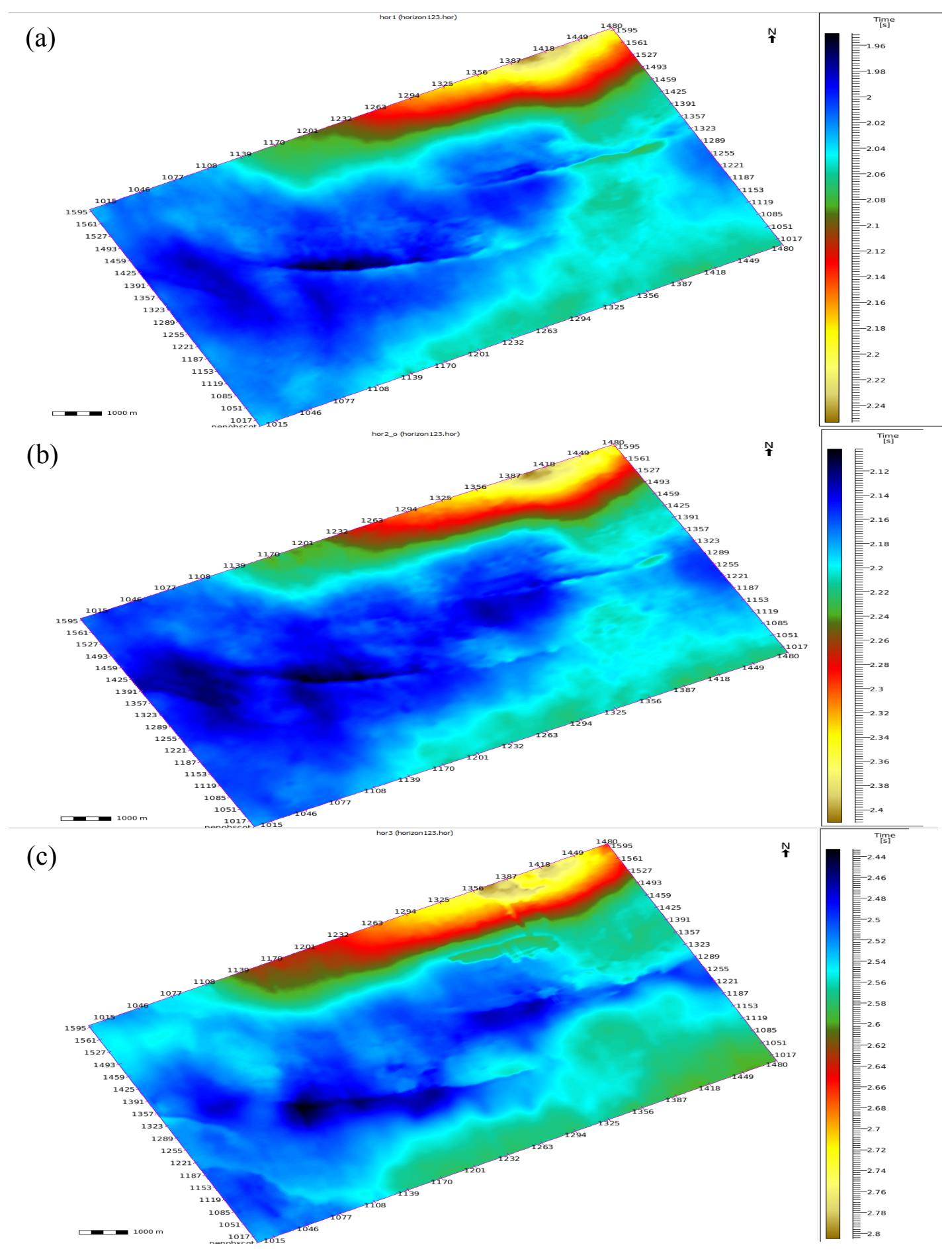

Figure 3.5. Three horizons used in this study in map view. The color blue to yellow stands for two - way travel time from short to long. From (a) to (c) are Horizon 1, Horizon 2, and Horizon 3. 


\subsubsection{Synthetic Seismograms}

A synthetic seismogram is a basic tool for correlating geological data from well logs with seismic data. Here Ricker wavelet was first assumed, and the reflection coefficient series is determined from the sonic and density logs. The synthetic seismogram is the result of the convolution of the reflection coefficient series and the wavelet. This is expressed mathematically in Equation 1, where $t$ is time in seconds, $\mathrm{R}$ is the reflection coefficient, $\mathrm{W}$ is the wavelet, $\mathrm{N}$ is the noise, and $\mathrm{S}$ is the synthetic. Finding suitable reflection coefficients and seismic wavelets are important parameters for seismic well ties.

$$
S(t)=W(t) * R(t)+N(t)
$$

Seismic data is recorded and displayed in time, but log data is in depth. The purpose of the synthetic seismogram is to obtain a reliable time-depth relationship to use for comparing log data to seismic data. The synthetic seismograms for wells L-30 and B41 are shown in Figures 3.6 and 3.7, using the initial Ricker wavelet with center frequency $25 \mathrm{~Hz}$. Included in these figures are the initial Ricker wavelet, synthetic seismogram, and the acoustic impedance log. Acoustic impedance (AI) is the product of the density $(\rho)$ and the velocity $(v)$ in one layer. Given the same formation in an adjacent layer one compare the reflection coefficient at the interface. It is expressed mathematically in Equation 2:

$$
R=\frac{A I_{2}-A I_{1}}{A I_{2}+A I_{1}}, A I=\rho v
$$




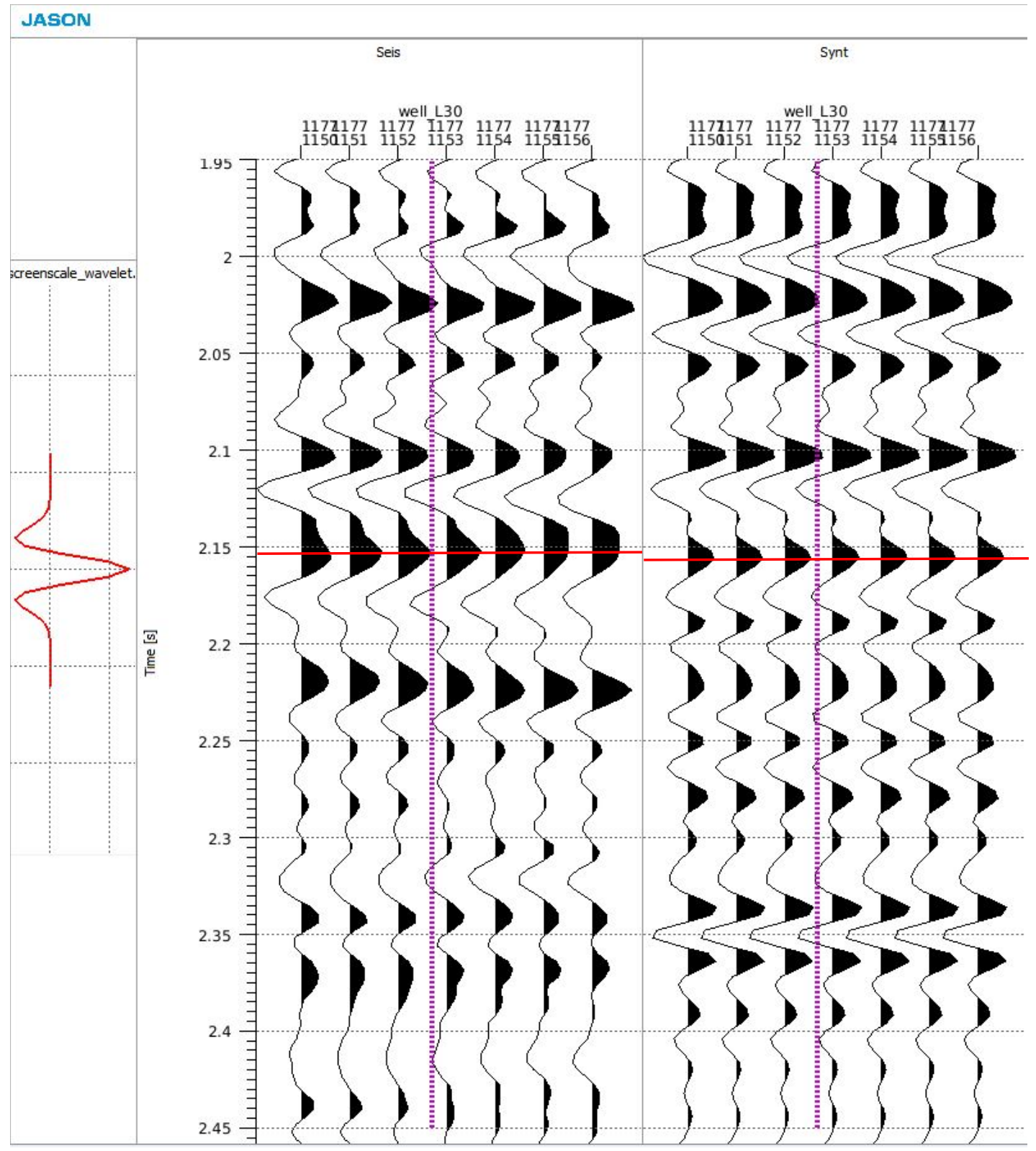

Figure 3.6. Well L-30 located in the inline 1177, in this section, the first panel is the Ricker wavelet, the second panel contains seismic traces near well L-30, and the third panel contains the synthetic seismogram for well L-30. Two red lines represent wave crest before "stretch and squeeze" note that they are not aligned. The purple line shows for the L-30 well location. 


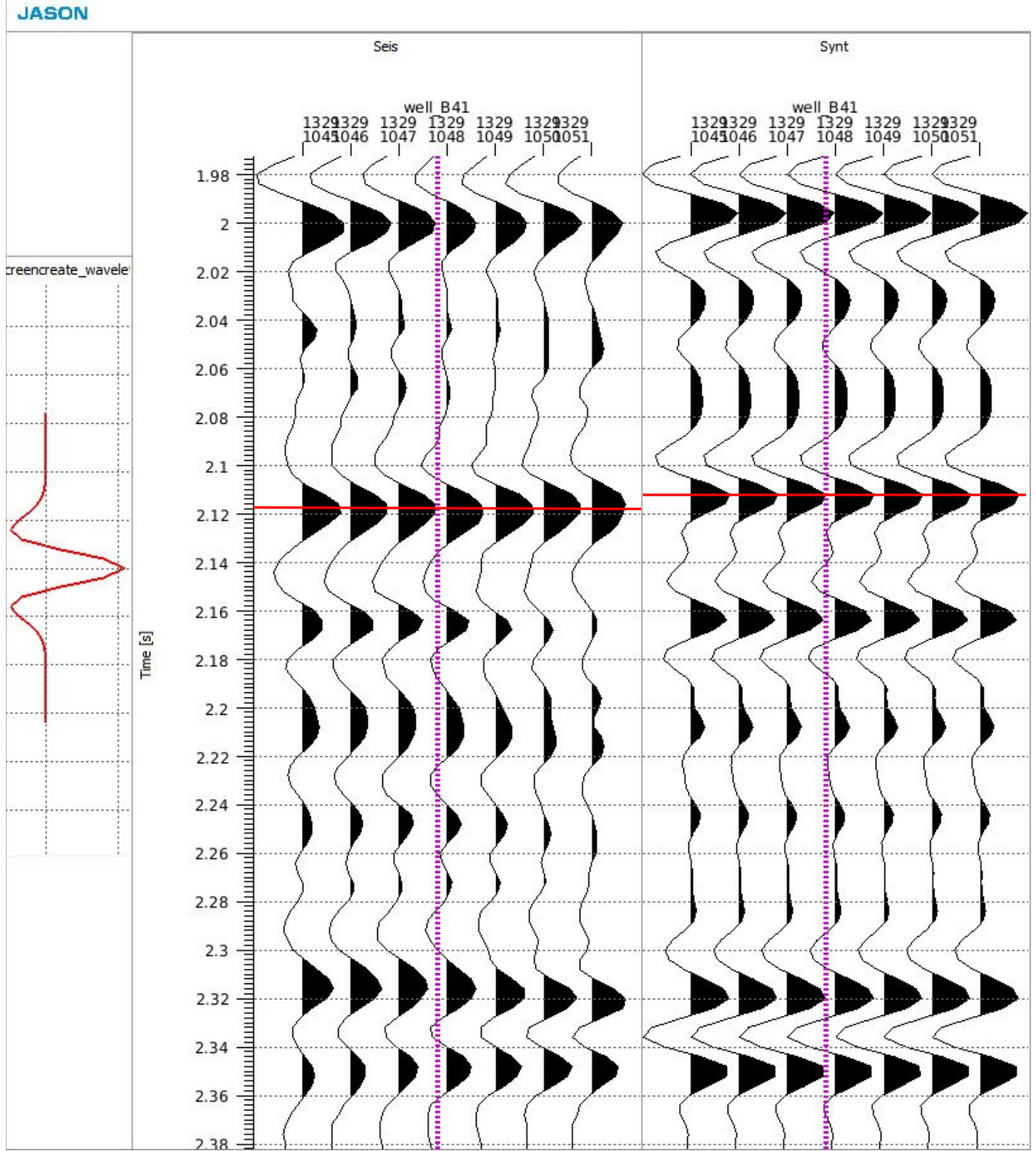

Figure 3.7. Well B-41 located in the inline 1329, in this section, the first panel is the Ricker wavelet, the second panel contains seismic traces near well B-41, and the third panel contains the synthetic seismogram for well B-41. Two red lines represent wave crest before "stretch and squeeze" they are not aligned. The purple line shows for the B-41 well location.

We can see from Figure 3.6 and 3.7 that the initial well-tie from a simple wavelet is fairly good, enabling us to proceed to the next step, in which we obtain higherresolution wavelets and improved well-ties. 


\subsubsection{Wavelet Estimation and Seismic Well Tie}

In order to obtain a reliable synthetic seismogram, it is necessary to obtain a correct time-depth relationship, applying application of a static time shift representing shallow (unlogged) velocities, then "stretch and squeeze" the synthetic data (effectively modifying the sonic log to seismic frequencies) to best match the seismic data near the well. A window of time near the target zone, $1000 \mathrm{~ms}-2800 \mathrm{~ms}$, was chosen for this exercise. Figures 3.8 and 3.9 show the final seismic well tie results from well L-30 and well B-41 using a non-Ricker wavelet found to obtain the best fit. These figures are comprised of a total of three panels showing the wavelet (after wavelet estimation for each well), seismic traces near the wells, and the synthetic seismogram. The resulting seismic synthetic correlation is $77 \%$ and $65 \%$ for wells L30 and B-41, respectively. However, correlation is not an absolute factor proving the seismic well tie is correct, but it is a prerequisite for judging whether or not the well tie is good before the inversion is performed.

The seismic well tie matched the synthetic data to the seismic data, confirming that a correct time-depth relationship was found after minor adjustments. In Figures 3.6 and 3.7, the seismic traces do not align perfectly between the synthetics and the actual recorded data, but after a very minor "stretch" they align (Figures 3.8 and 3.9) perfectly. 


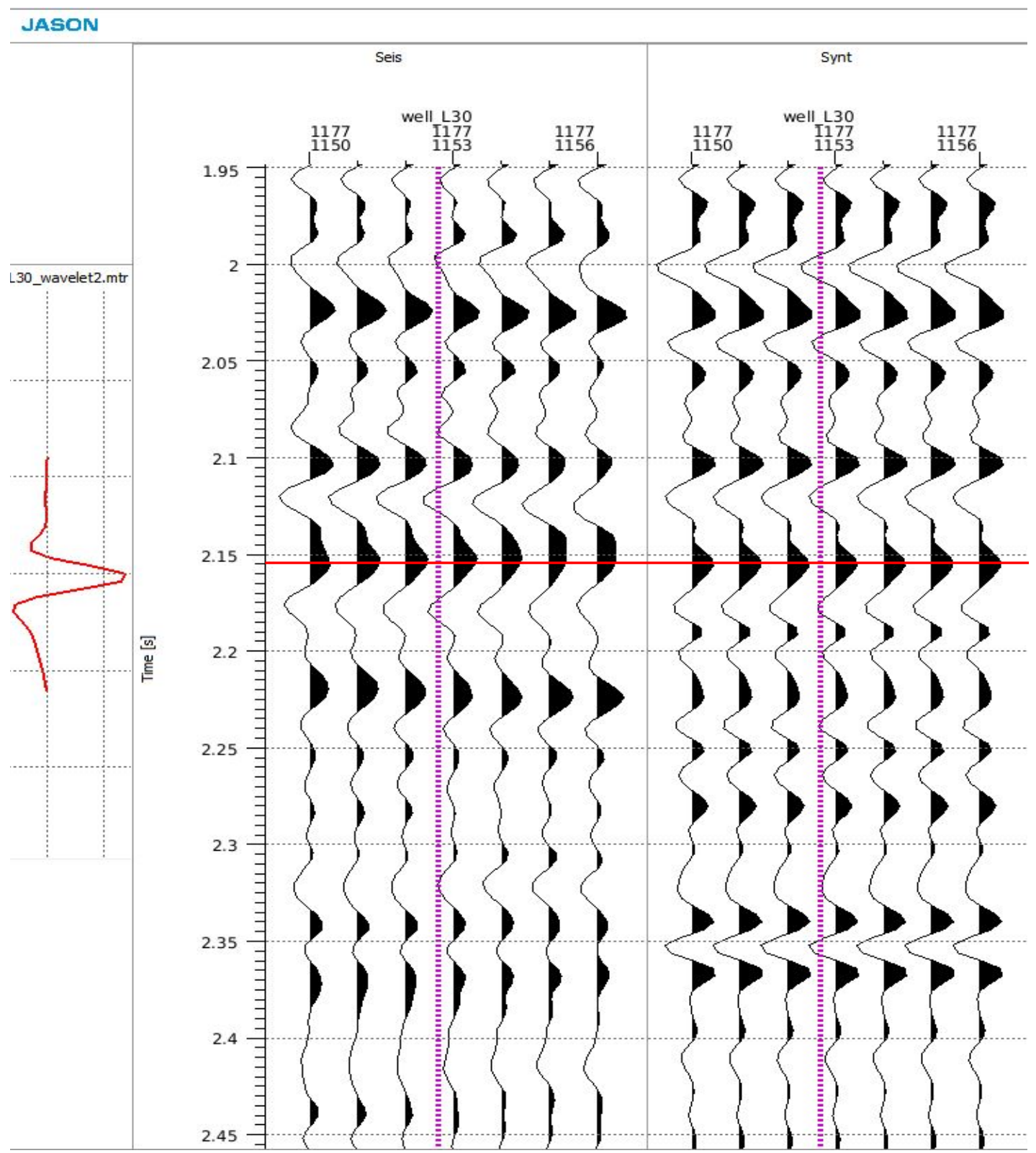

Figure 3.8. Well L-30 located in the inline 1177, in this section, the first panel is the wavelet for well L-30 after wavelet estimation, the second panel contains seismic traces near well L-30, and the third panel contains synthetic seismogram for well L30. Two red lines represent wave crest after "stretch and squeeze". They are aligning, which is the step to find the time - depth relationship, and determine the seismic welltie for well L-30. The purple line shows for the well L-30 location. 


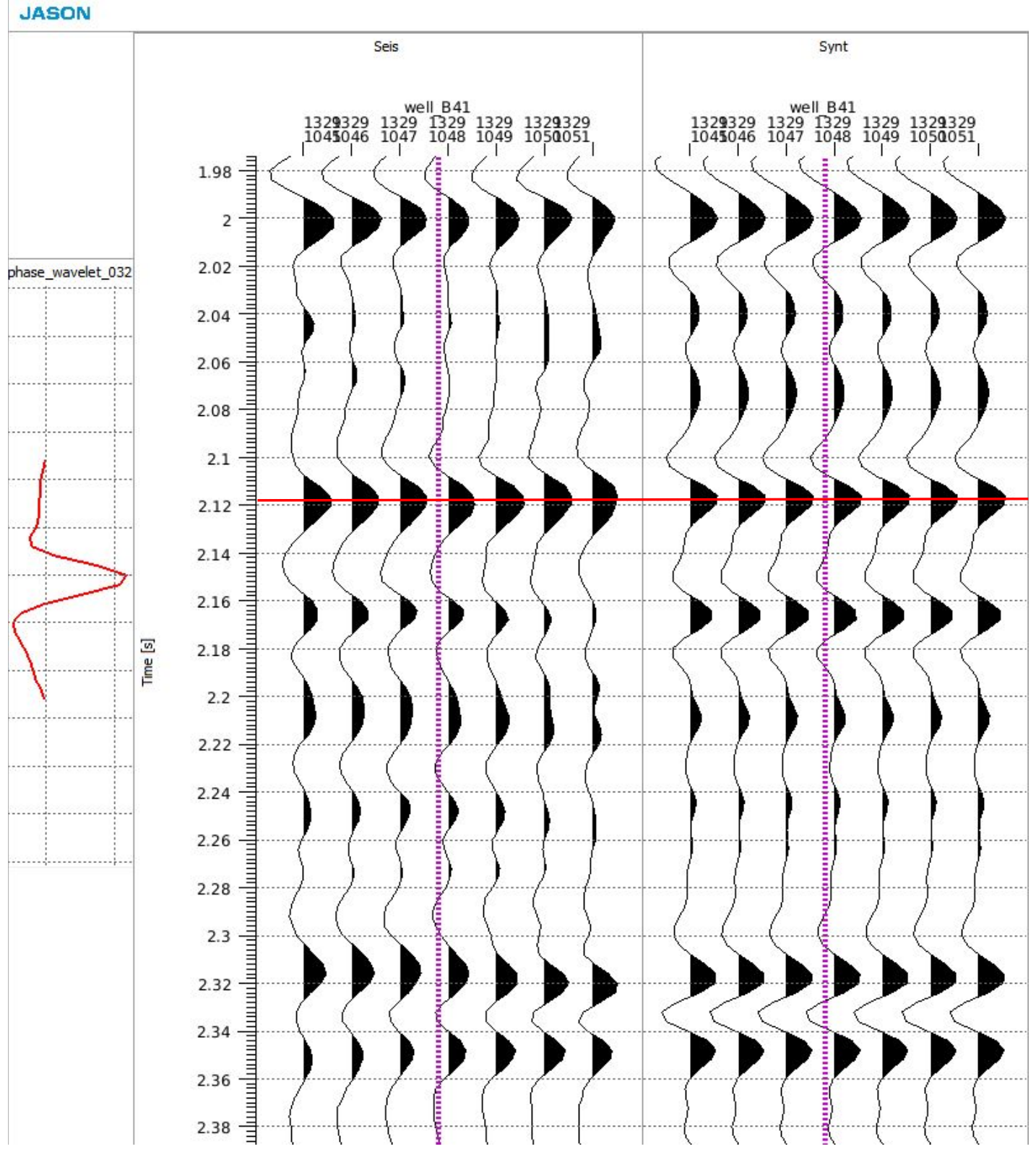

Figure 3.9. Well B-41 located in the inline 1329, in this section, the first panel is the wavelet for well B-41 after wavelet estimation, the second panel contains seismic traces near well B-41, and the third panel contains synthetic seismogram for well B41. Two red lines represent wave crest after "stretch and squeeze". They are aligning, which is the step to find the time - depth relationship, and determine the seismic welltie for well B-41. The purple line shows the well B-41 location. 
A wavelet represents a match factor link between seismic record and the based model in the inversion. High precision wavelet extraction is an important factor for inversion, after modifying the time - depth relation, and I can extract a suitable wavelet for each well (Wang \& Lu, 2011). After the seismic well tie and wavelet estimation of the two wells were completed, the average wavelet of the two were obtained and used for the CSSI process. A small difference between these two wavelets permit an assumption that the average wavelet is reliable as shown in Figure 3.10.

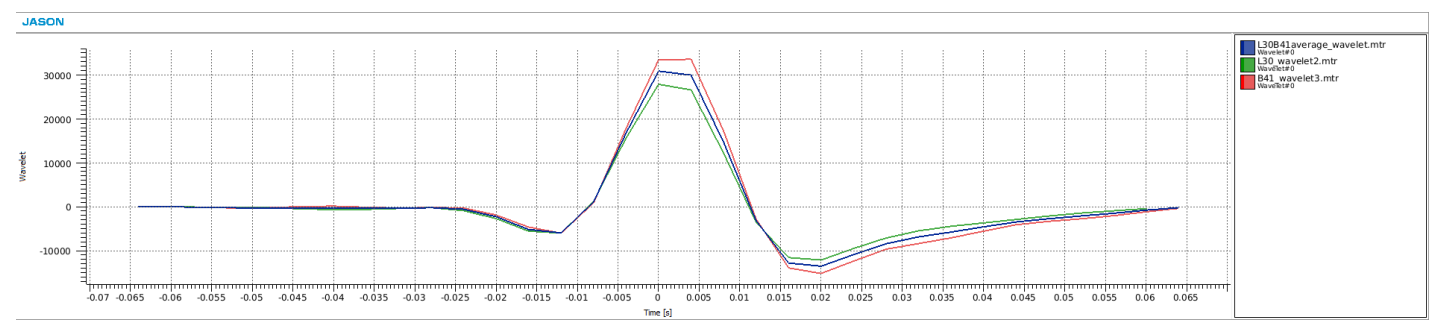

Figure 3.10. Average wavelet after wavelet estimation of wells L-30 and B-41. The green wavelet is the wavelet for the well L-30 after the wavelet estimation, the red wavelet is the wavelet for the well B-41 after the wavelet estimation, and the blue one is the average wavelet.

\subsubsection{Inversion}

The spectrum of the seismic data, shown in Figure 3.11, shows the frequency range of the seismic data to lie between $8 \mathrm{~Hz}$ and $40 \mathrm{~Hz}$, so building a low frequency model is a necessary step for inversion to recover the low frequency component, i.e. that below $8 \mathrm{~Hz}$ (Wang \& Lu, 2011). There are three steps to building a low frequency model. The first step is to create a framework based on the horizons previously tracked. The second step generates a broadband model based on the AI calculated from well logs, propagated throughout the volume, following the tracked horizons. Figure 3.12 shows the broadband model section cross the two wells, this section view 
is different from the inline view and the crossline view, being an arbitrary line between wells L-30 and B-41 (the green line shown in Figure 3.1). In the final step, the broadband model is filtered using a low pass filter $(8 \mathrm{~Hz})$ yielding the low frequency model (shown later in Figure 3.17 (a)).

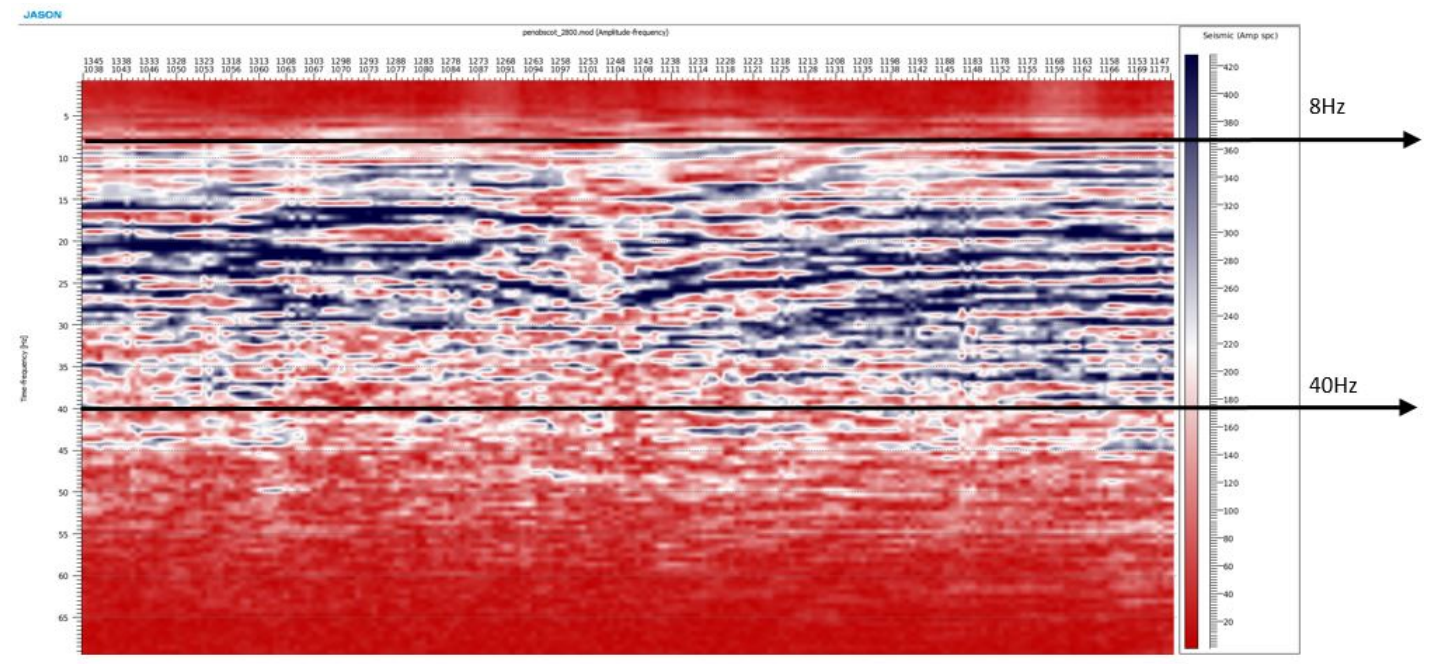

Figure 3.11. Frequency range of Penobscot 3D seismic data, shown on the arbitrarily line section view (Figure 3.1), blue colors have higher spectral content than red colors. After the broadband model is built, the inversion process itself is started. Seismic data, estimated wavelet, estimated horizons, the trace gate, QC wells, QC time gate, and QC traces were all inputs for the process. 


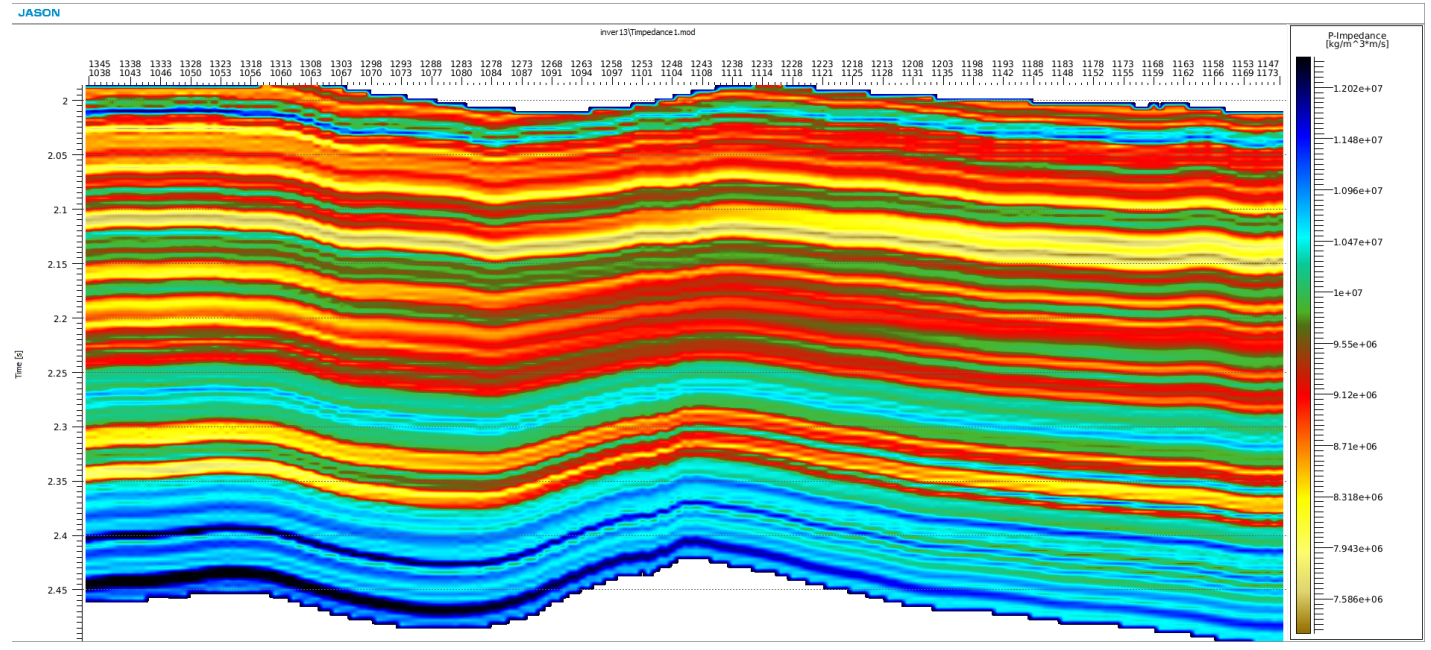

Figure 3.12. Broadband model of Penobscot 3D seismic data in the arbitrary line, intersecting the two wells (Figure 3.1).

The most important factor in this inversion process is the testing of sensitive QC parameters (Figure 3.13): Contrast Misfit P-impedance Uncertainty, Seismic Misfit Signal to Noise Ratio, Merge Cutoff Frequency, and Wavelet Scale Factor Seismic. Seismic Misfit Signal to Noise Ratio controls the weight of seismic data; it is used to constrain the similarity between inversion results and seismic data. If the signal to noise ratio is high, then the correlation between synthetic and seismic data is also high. Contrast Misfit P-impedance Uncertainty controls the sparsity of the reflection coefficient sequence. If it is small, the reflection coefficient sequence is sparser. The wavelet for inversion is the average wavelet from two wells' wavelet estimations. Since the inversion time gate is different from the wavelet estimation time gate, it is important to set the Wavelet Scale Factor Seismic to a suitable value. 


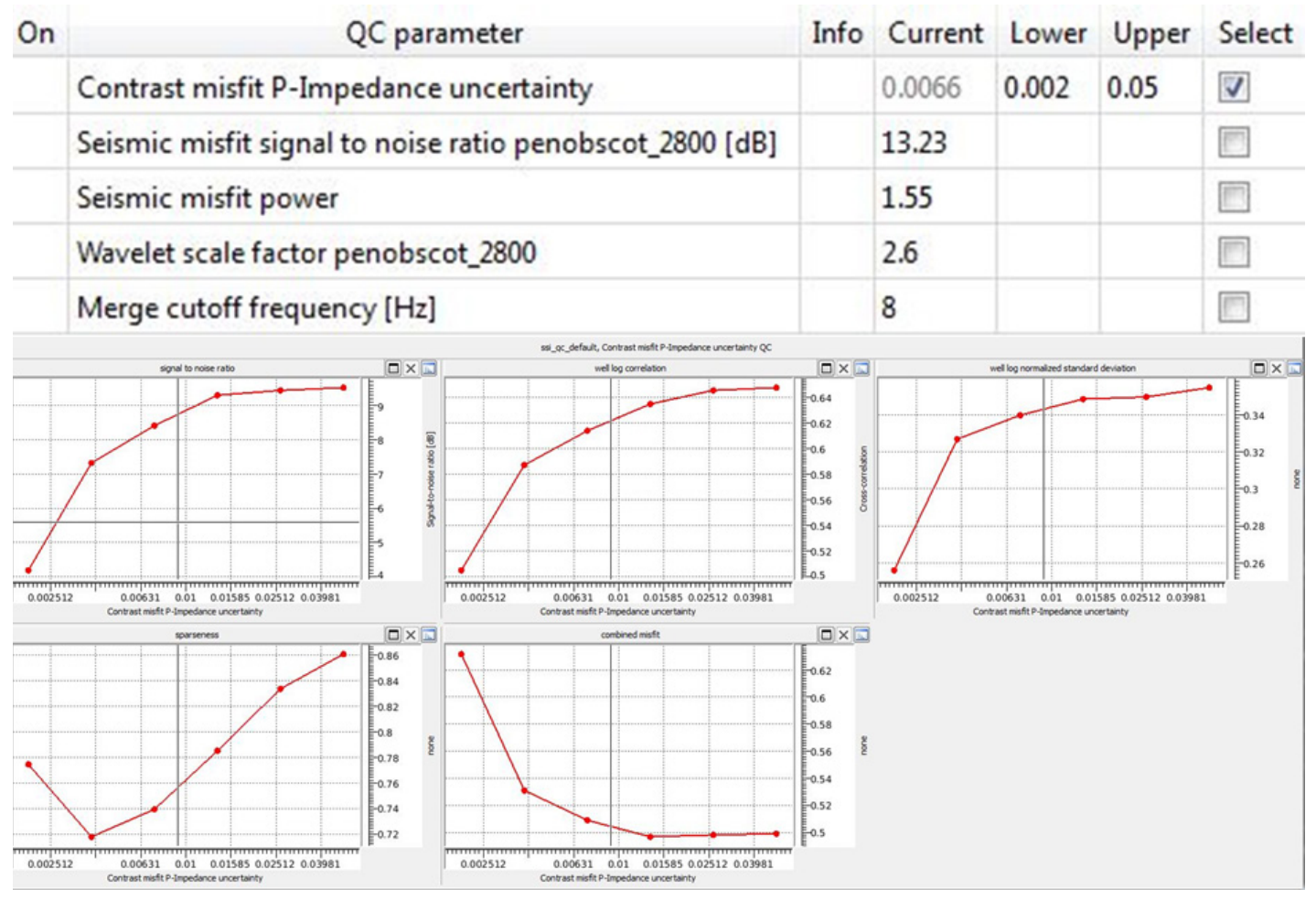

Figure 3.13. QC parameters setting.

For each iteration process, a test result can be analyzed based on the QC parameter values chosen. After selecting the optimal values for each QC parameter, initial results can be generated, showing the initial inversion result in the section view (Figure 3.14), and in 3D view (Figure 3.15).

The inversion process uses the low frequency model based on log data, combining that with the seismic-inversion results, because seismic data lacks a low frequency result, the low frequency result of the impedance inversion is neither stable nor reliable. The Merge Cutoff Frequency is used to decide the transition between the logbased low frequency model and the seismic-based inversion result. Choosing a suitable value for the cutoff frequency is an iterative process. The filters used in this study, with a transition at $8 \mathrm{~Hz}$, are shown in Figure 3.16. 


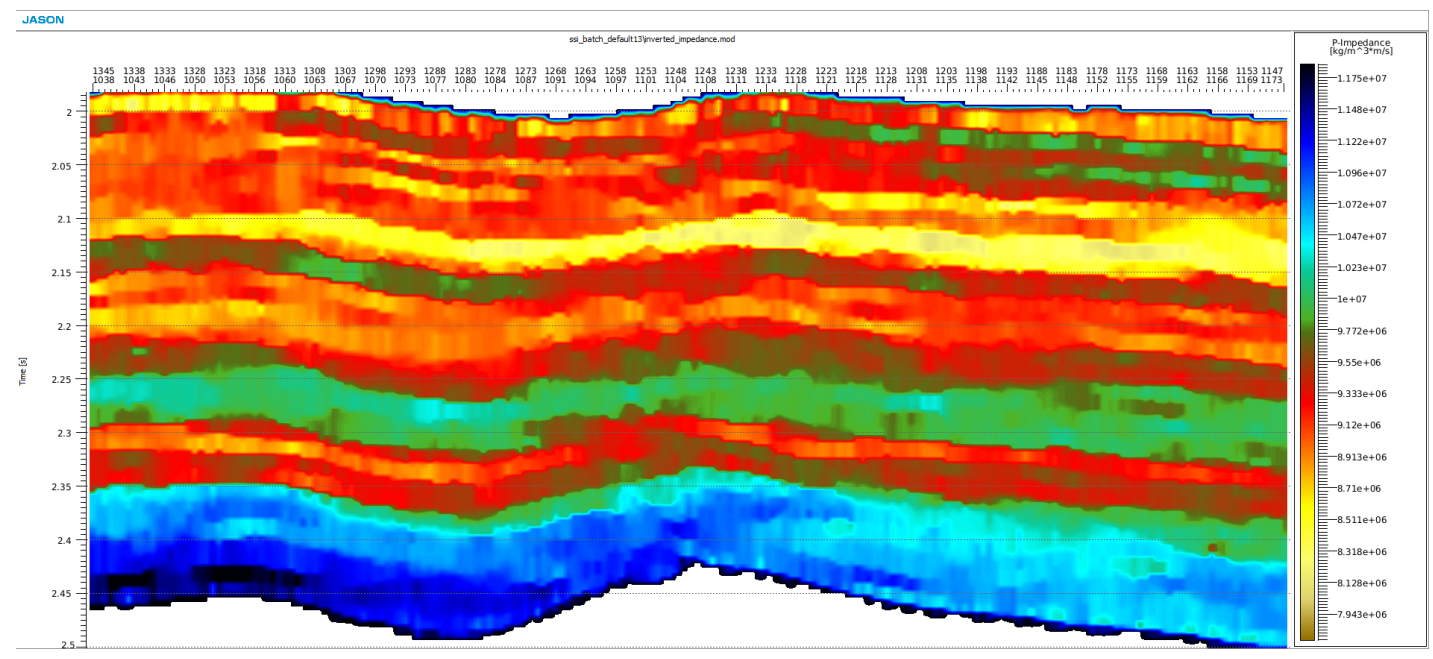

Figure 3.14. Initial inversion result of Penobscot 3D seismic data shown in the arbitrary line (Figure 3.1(b)) section view.

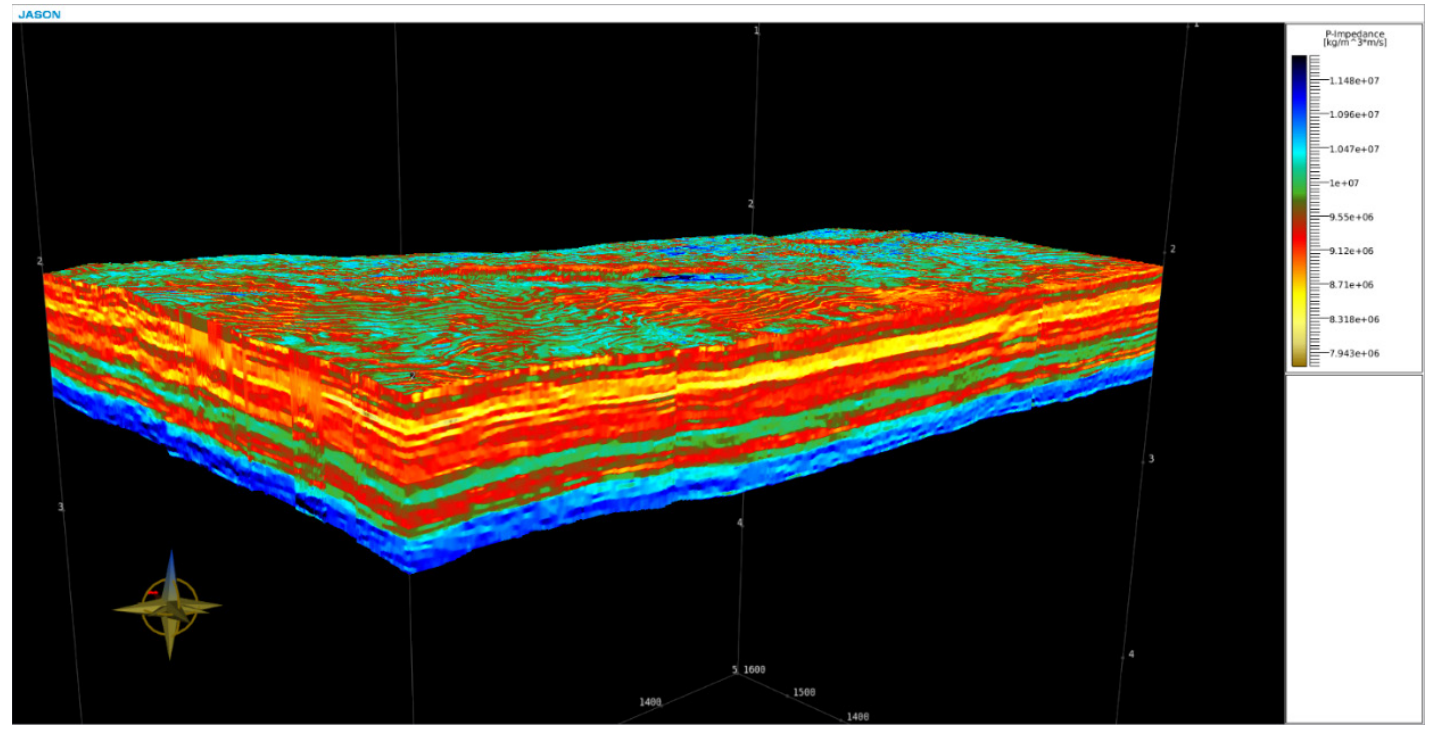

Figure 3.15. Initial inversion result of Penobscot 3D seismic data shown in 3D view. 


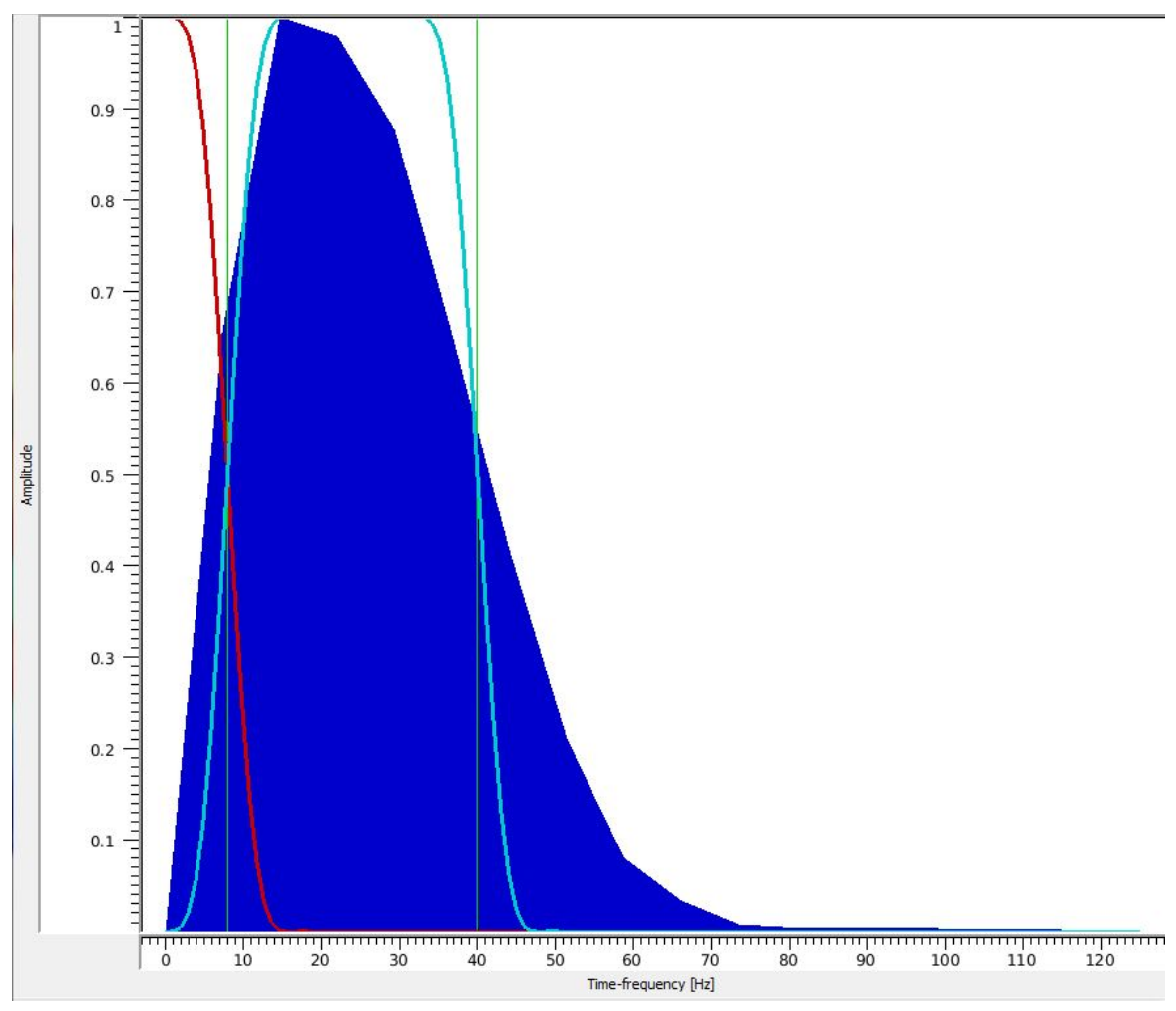

Figure 3.16. Filters used in this research. The red curve is the low pass filter $(8 \mathrm{~Hz})$ for the low frequency model and the light blue curve is the bandpass filter $(8-40 \mathrm{~Hz})$ for the initial inversion result, the solid blue color is the spectrum of the Penobscot seismic data.

The last step is Trace Merging, which merges the low frequency band information with the seismic bandwidth information. Figure 3.17 shows the low frequency model after using the low pass filter $(8 \mathrm{~Hz})$, the inversion result after using the bandpass filter $(8-40 \mathrm{~Hz})$, and the final merged result. The 3D view for the final inversion result is shown in Figure 3.18. The comparison of the merged result (Figure 3.17 (c)) with initial inversion result (Figure 3.14) demonstrates the value of filtering and merging; the final inversion result is clearer and more reliable. 


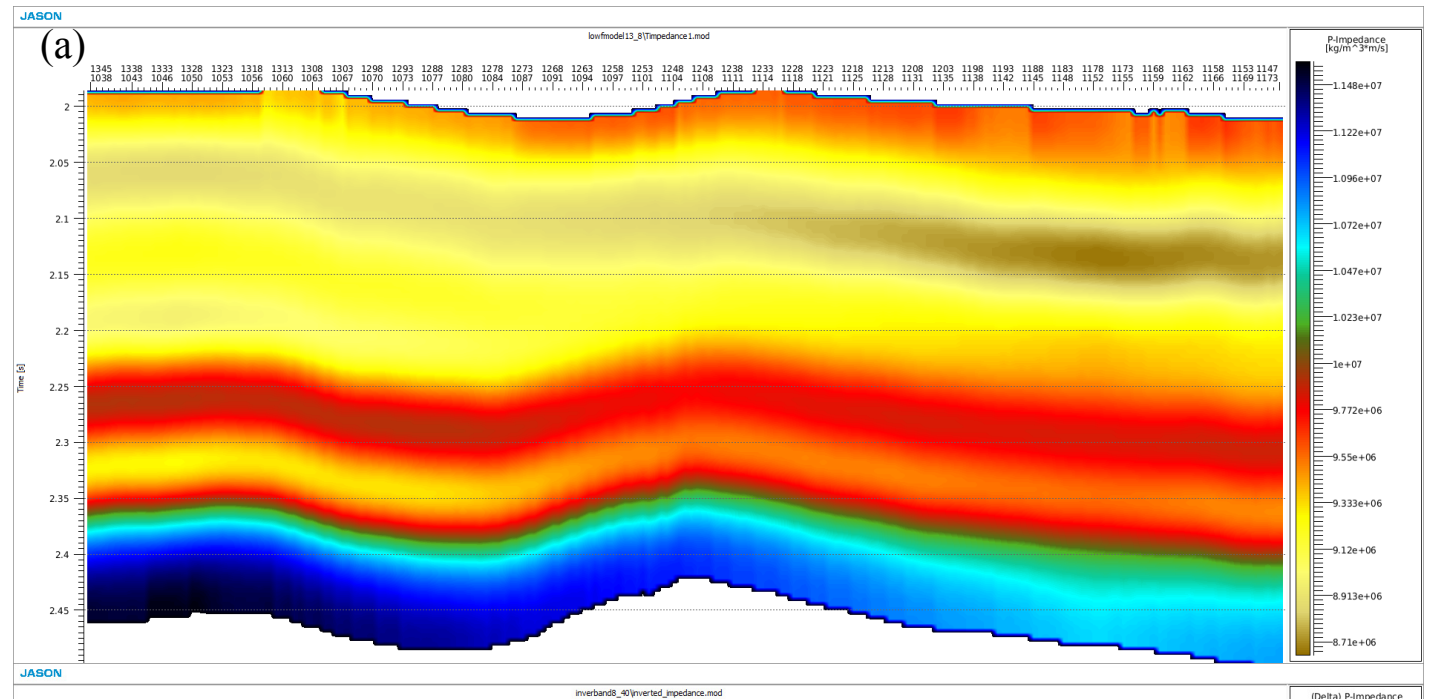

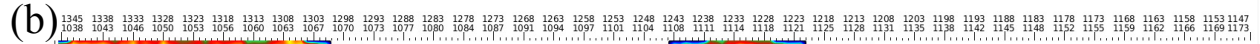

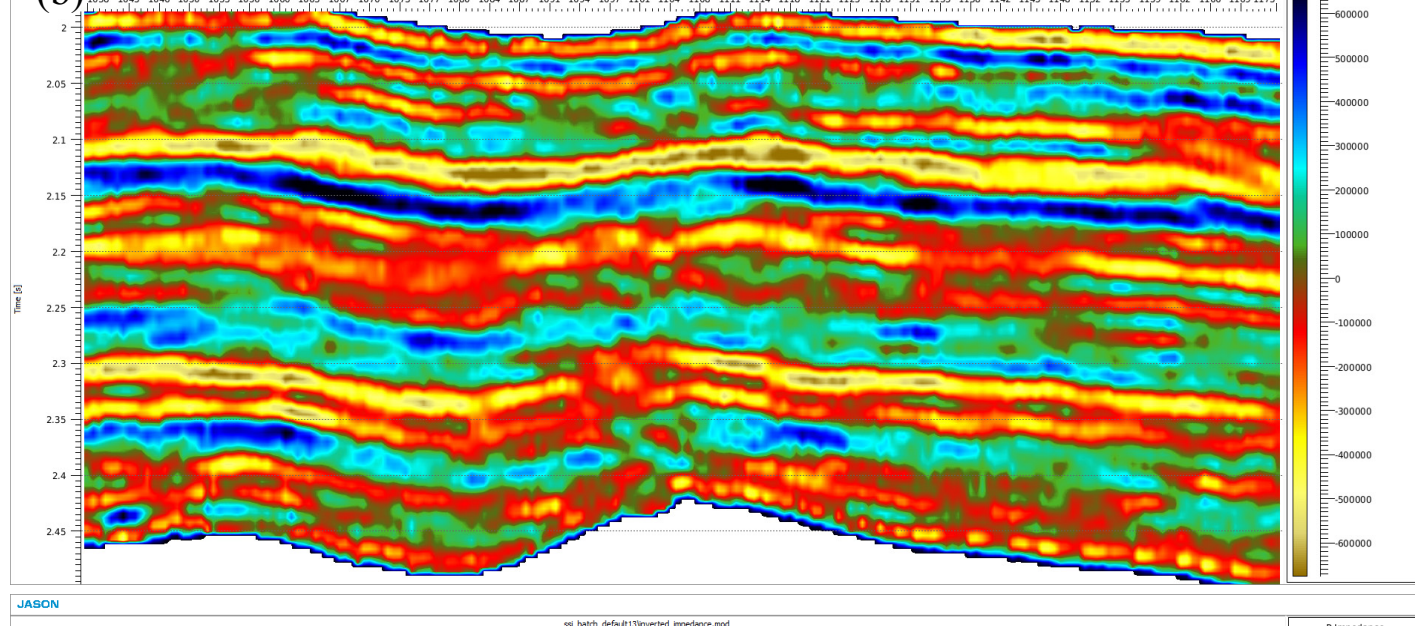

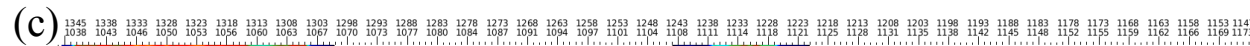

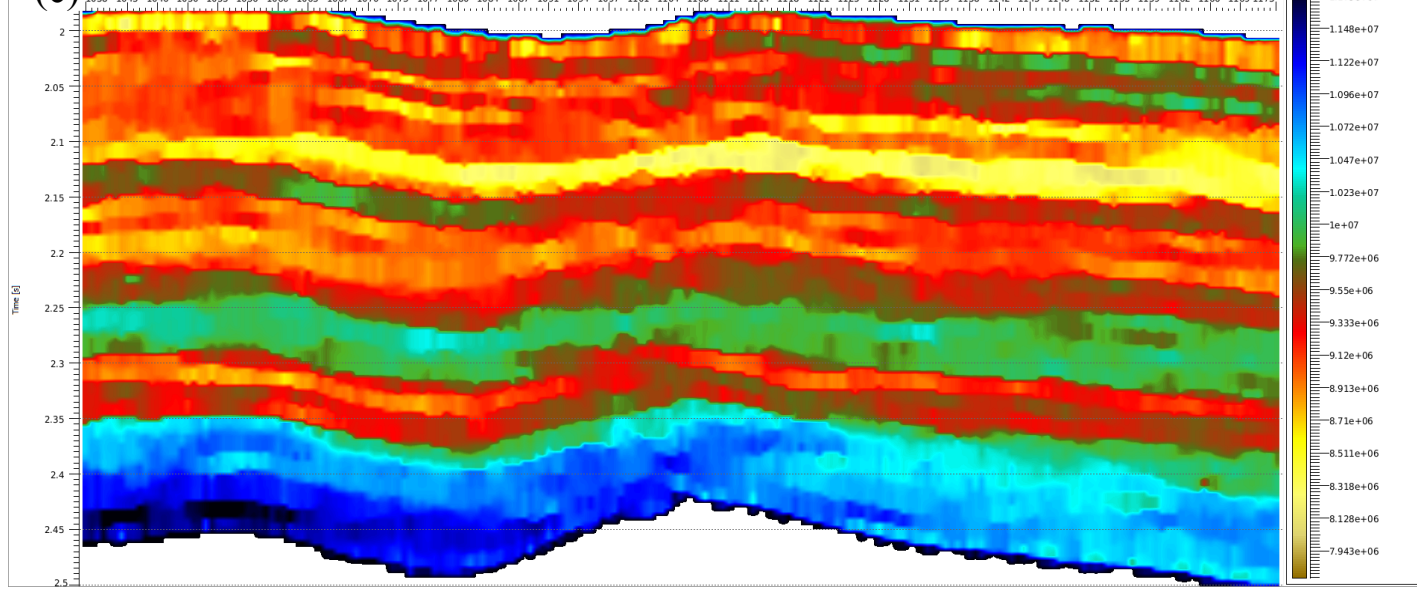

Figure 3.17. (a) Low frequency model after using low pass filter. (b) Initial inversion result after using bandpass filter. (c) Final inversion result after merging (a) and (b). 


\section{Seismic Results and Comparison with Log Data}

Gamma Ray (GR) logs and Spontaneous Potential (SP) logs are used to identify the potentially commercial zone at the well locations in this study (Dewan, 1983). Figure 4.1 shows the final inversion result in section view, with GR logs superimposed; there are depths with low GR values observed in well L-30 and B-41, illustrating the presence of a sand layer that could contain hydrocarbons. Figure 4.2 shows both the SP curves and GR curves, and the low values of SP (clean sand) are located at the low values of GR, suggesting high permeability. For these reasons, the layer of low GR and SP is identified and chosen as the target layer for this study. The inversion results show that the acoustic impedance is also low (the yellow region between the two black lines in Figure 4.1), implying high porosity and/or hydrocarbon content, suggesting it may have properties of a potentially commercial zone (Wang, et al., 2006). The next step is to examine the inversion volume to identify regions where there is a well-developed continuous sand layer worth further exploration; we do this through identification of low-impedance "bodies" and mapping them.

Body Checking is useful to obtain "bodies" of low impedance. This study limited body checking to the layer of low impedance identified in Figure 4.1 located between two black lines. For this purpose, various cutoff values for low impedance were investigated. The lowest impedance found within the target layer is $7.9 \times 10^{6}$ $\mathrm{kg} / \mathrm{m}^{3 *} \mathrm{~m} / \mathrm{s}$. We obtained five relative thickness maps for five different impedance ranges as detailed in Appendix I. 


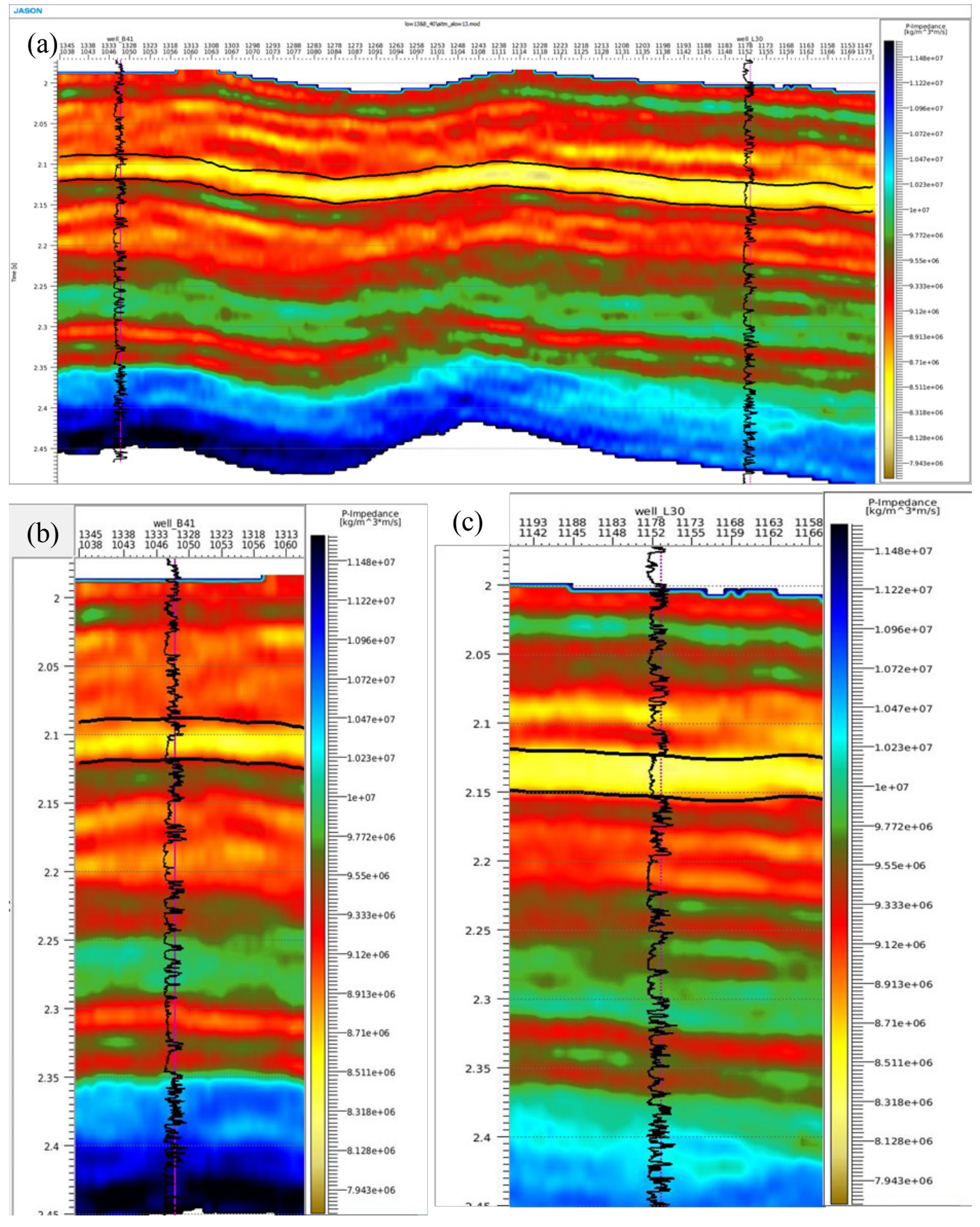

Figure 4.1. (a) GR logs are shown on final inversion result in section view across the two wells. (b) GR $\log$ for the well B-41 shown on final inversion result. (c) GR log for the well L-30 shown on final inversion result. Between the two black lines the low impedance layer matches the low GR and SP values. 

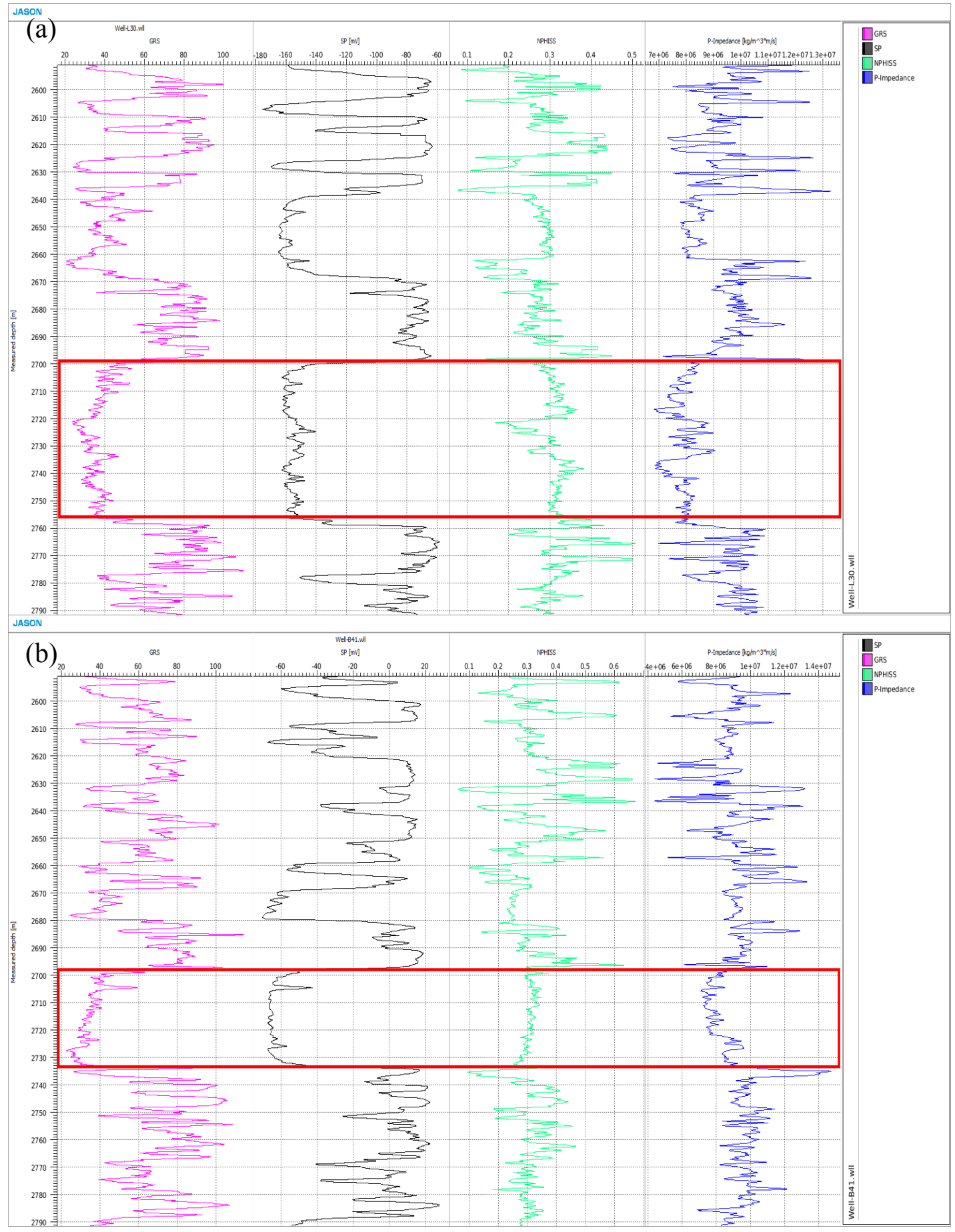

Figure 4.2. Low GR and SP values indicate a sand layer. (a) GR, SP, Neutron Porosity, and impedance curves for the well L-30. (b) GR, SP, Neutron Porosity, and impedance curves for well B-41. The red square area is the target sand layer. 
These thickness maps show thickness as Two-Way travel Time (TWT). Using thickness values in time units for the two well positions where both true thickness and TWT are known, calculations were performed to convert the thickness into depth units. The average velocity for this sand layer is $3933.5 \mathrm{~m} / \mathrm{s}$. Using Equation 3, where $H_{n}$ is the thickness for the $\mathrm{n}^{\text {th }}$ impedance interval map, TWT is the thickness time (two-way travel time) read from the map, and $\bar{v}$ is the average velocity $(3933.5 \mathrm{~m} / \mathrm{s})$, layer thickness was obtained.

$$
H_{n}=\frac{T W T}{2} * \bar{v}
$$

Every thickness map for each time unit gives a result of thickness in depth, all results for each map are shown in Figure 4.3 below. The five thickness maps, which use the same color scale, illustrate that the sand layer near well B-41 does not contain the very lowest impedance values, but the target sand layer near well L-30 shows very low impedance.

The thickness of low-impedance zones is of interest, but it would be more interesting to know the total pore volume within this thickness. Because we have well logs we can calibrate the acoustic impedance to porosity for the sand layer. The relationship between Acoustic Impedance (AI) and Neutron Porosity are shown in Figure 4.4 as a crossplot and log presentations for both wells shown in Figure 4.2. The log data of well L-30 used for the crossplot is between $2698.09 \mathrm{~m}$ to $2756.76 \mathrm{~m}$, and the log data of well B-41 used for the crossplot is between $2696.57 \mathrm{~m}$ to $2734.06 \mathrm{~m}$, which only includes the target sand layer. 


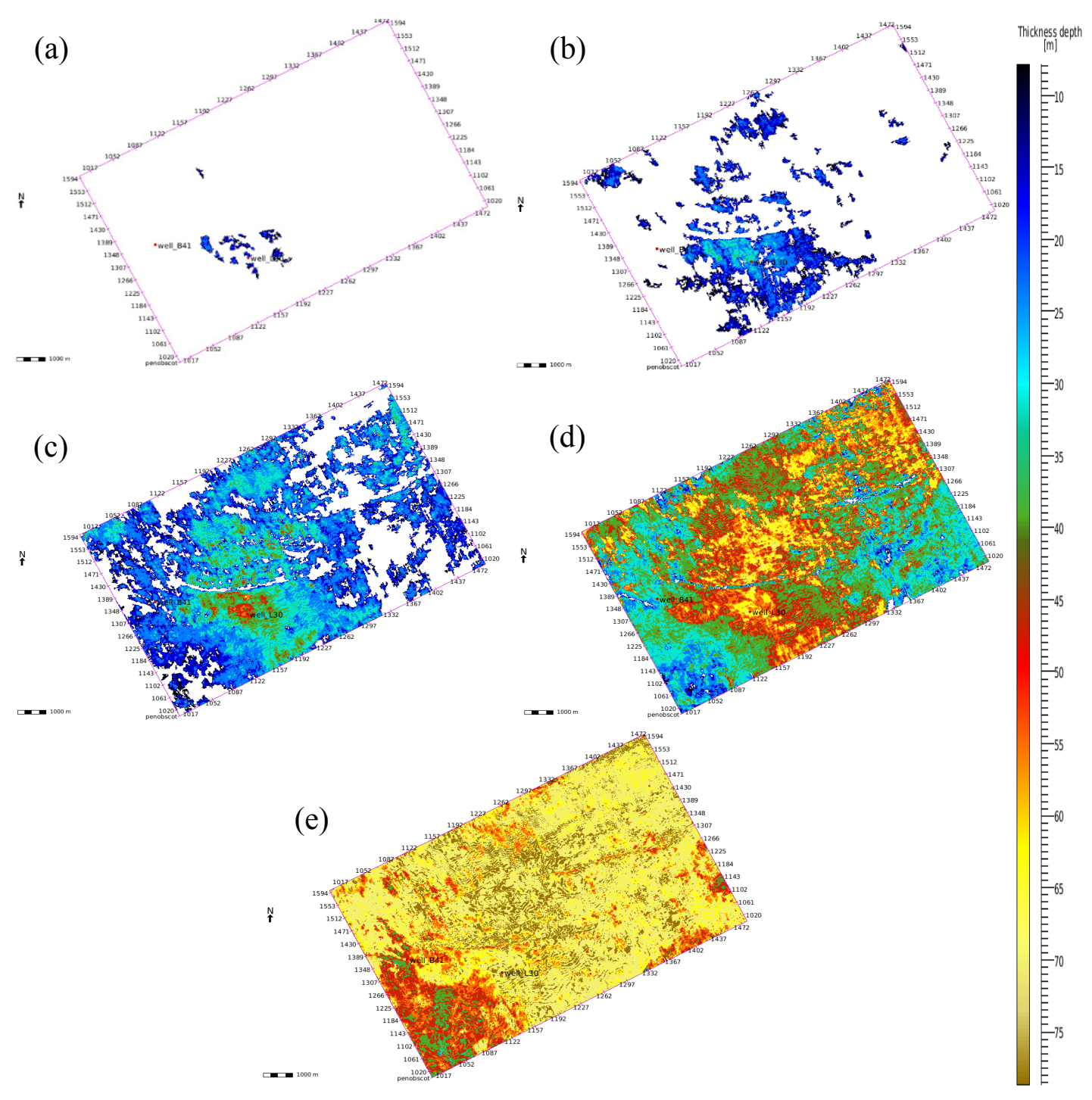

Figure 4.3. The thickness map (depth unit) of different impedance ranges, the lower limit of impedance is $7.9 \times 10^{6} \mathrm{~kg} / \mathrm{m}^{3 *} \mathrm{~m} / \mathrm{s}$, but the upper limit numbers are different: (a) $8.2 \times 10^{6} \mathrm{~kg} / \mathrm{m}^{3 * \mathrm{~m}} / \mathrm{s} \mathrm{(b)} 8.4 \times 10^{6} \mathrm{~kg} / \mathrm{m}^{3 * \mathrm{~m}} / \mathrm{s}$ (c) $8.6 \times 10^{6} \mathrm{~kg} / \mathrm{m}^{3 *} \mathrm{~m} / \mathrm{s}$ (d) $8.8 \times 10^{6}$ $\mathrm{kg} / \mathrm{m}^{3 *} \mathrm{~m} / \mathrm{s}$ (e) $9.0 \times 10^{6} \mathrm{~kg} / \mathrm{m}^{3 *} \mathrm{~m} / \mathrm{s}$. These five maps use one color scale.

From the crossplot, we see the strong clear trend of AI as a function of porosity and impedance in the sands (yellow points). The line through the yellow points uses a linear function to describe the relationship between AI and porosity, which is expressed mathematically in Equation 4:

$$
\operatorname{porosity}(\varnothing)=0.508364-2.52513 * 10^{-8} * A I
$$




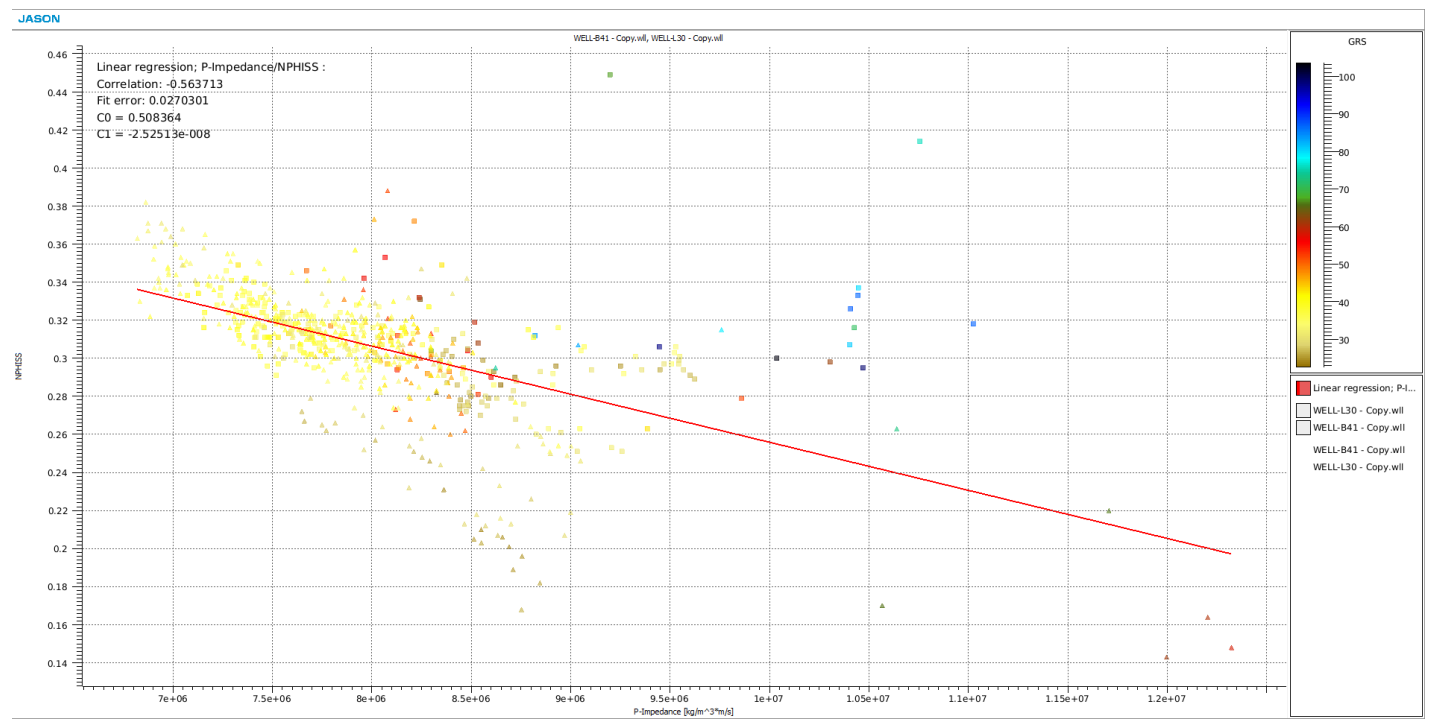

Figure 4.4. The relationship between impedance and porosity. The log data used in the crossplot are shown in the red squares (Figure 4.2). The color stands for the GR values. Square points represent well L-30 log data, and triangle points represent well B-41 log data. The red line through these yellow points indicates the linear function of porosity and impedance.

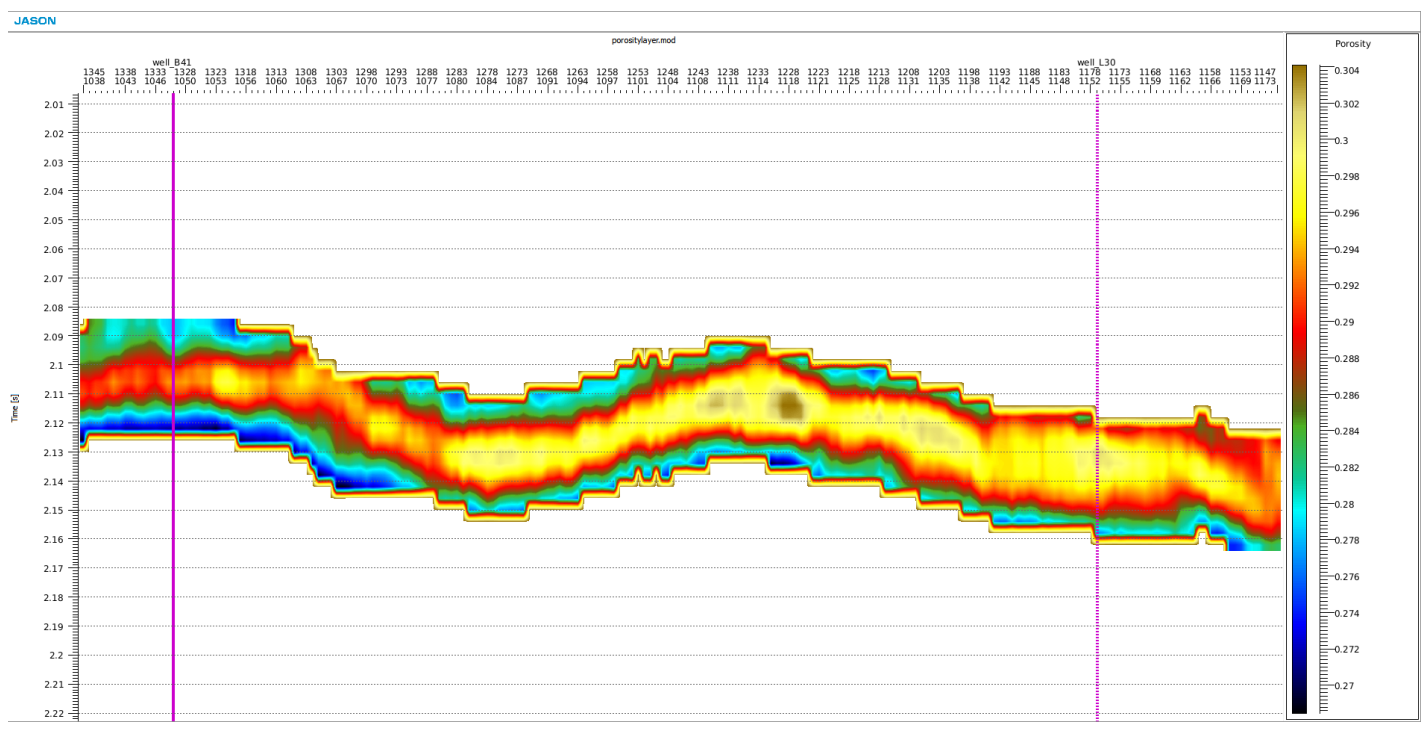

Figure 4.5. The Porosity of the target sand layer in section view, showing the arbitrarily line across the two well section. Two purple lines are well locations. 


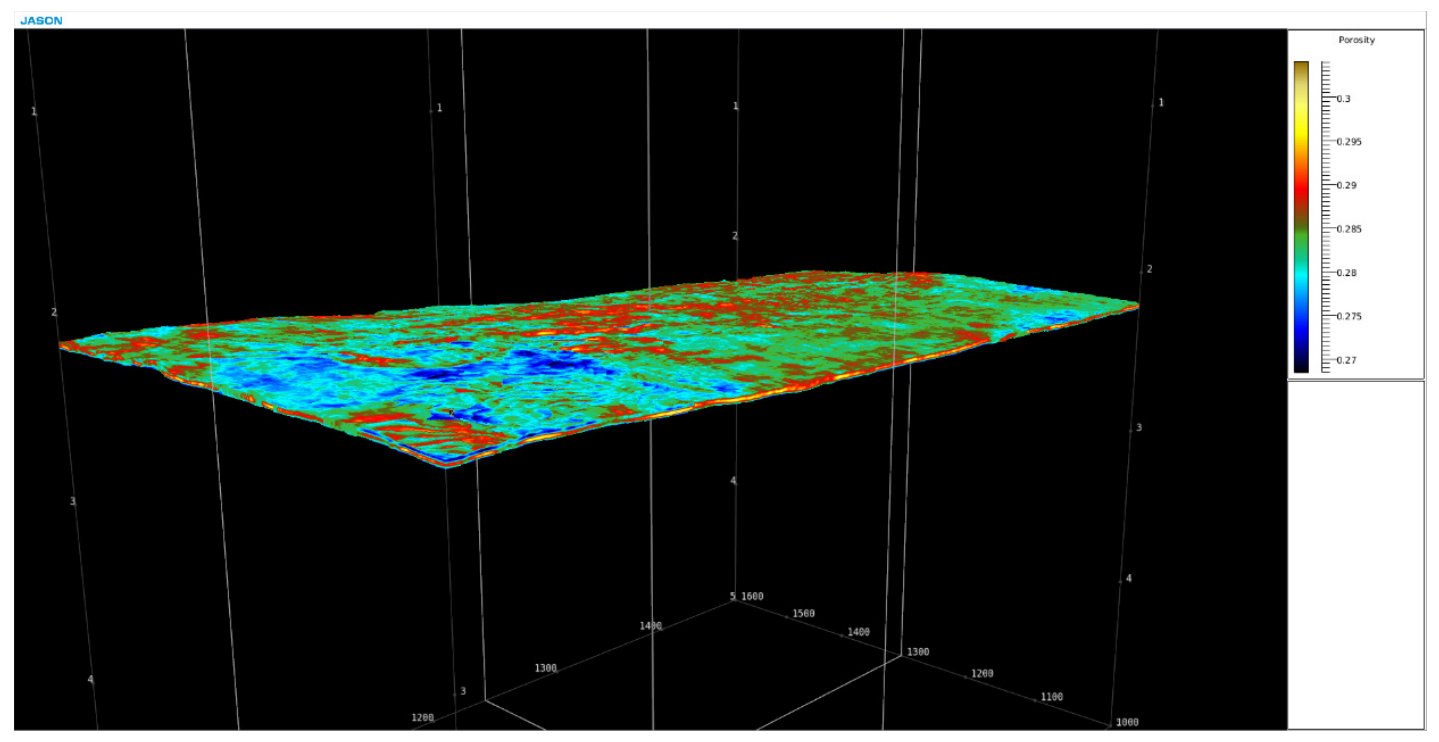

Figure 4.6. Porosity of the target sand layer in 3D view.

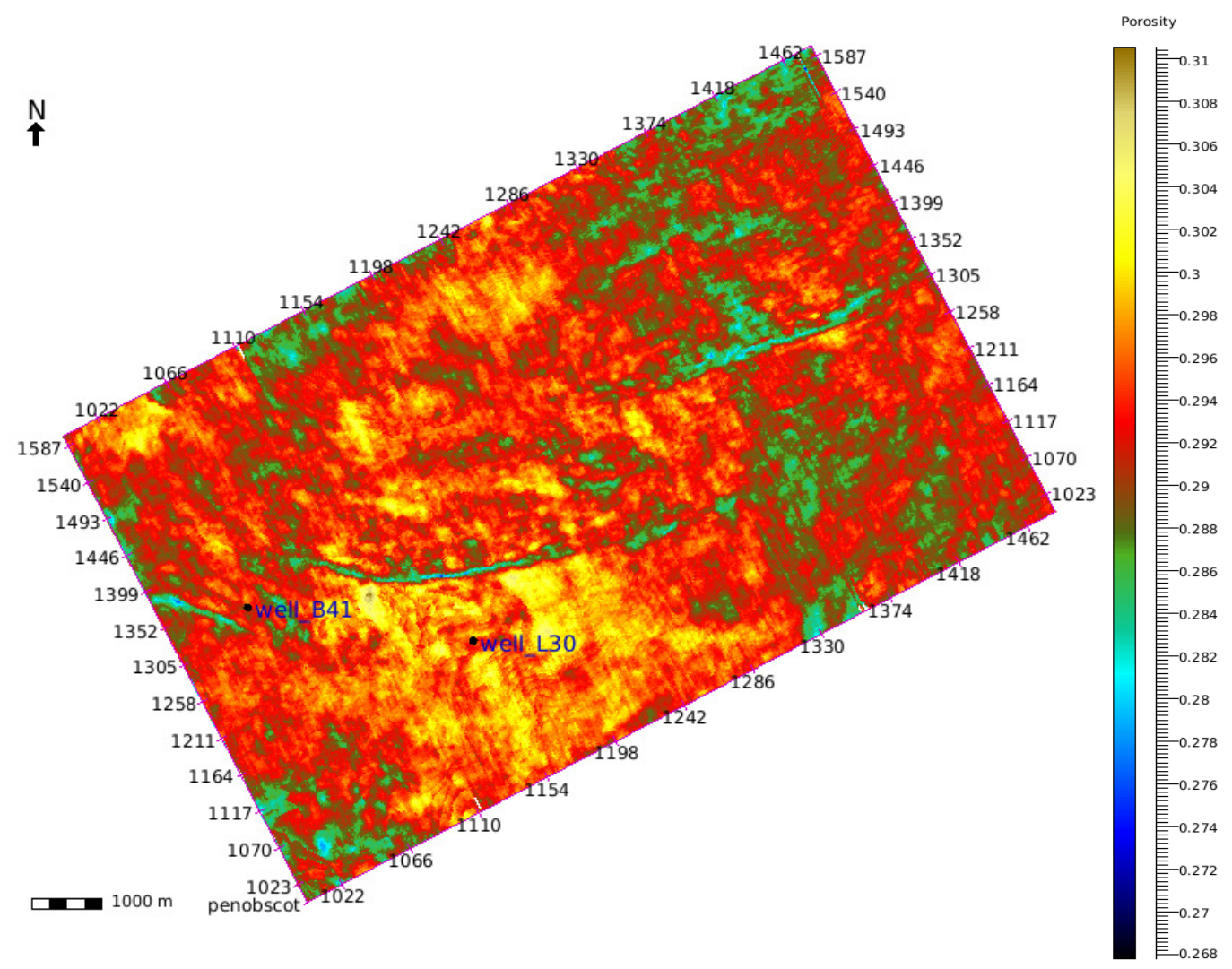

Figure 4.7. The porosity of the middle of the layer is shown in map view. Two black points are well locations. 
Porosity of the target sand layer is calculated, the results shown in section view (Figure 4.5) and 3D view (Figure 4.6). In this sand layer, the yellow part stands for high porosity. The porosity in the middle of the layer is shown in map view (Figure 4.7).

According to thickness and porosity, another important result, pore thickness, can be calculated. Figure 4.8 shows pore thickness of the sand layer for different impedance ranges. 
(a)

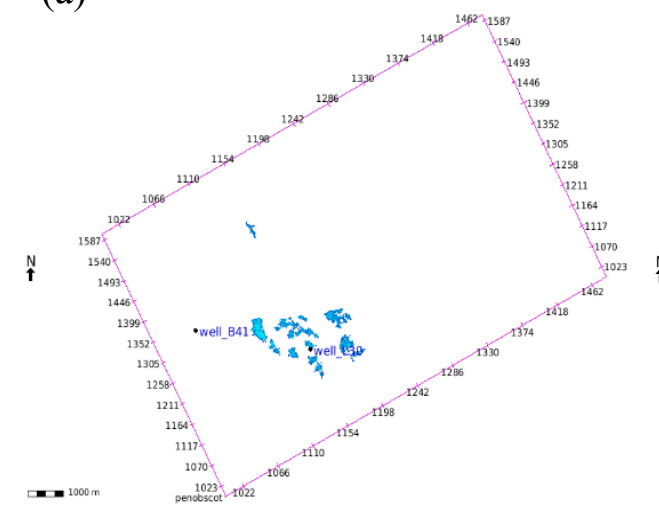

(c)

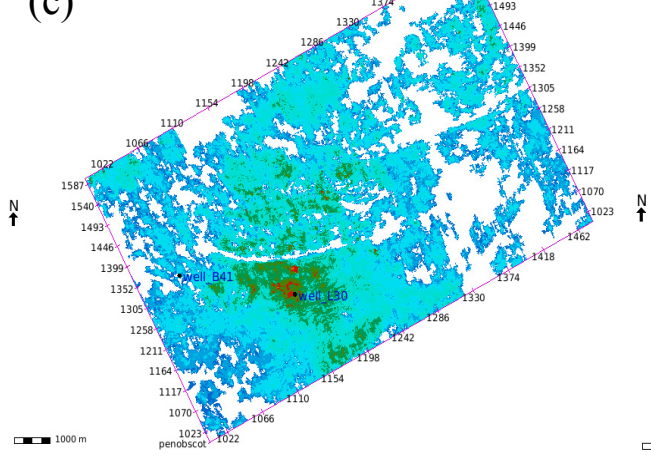

(e) (b)

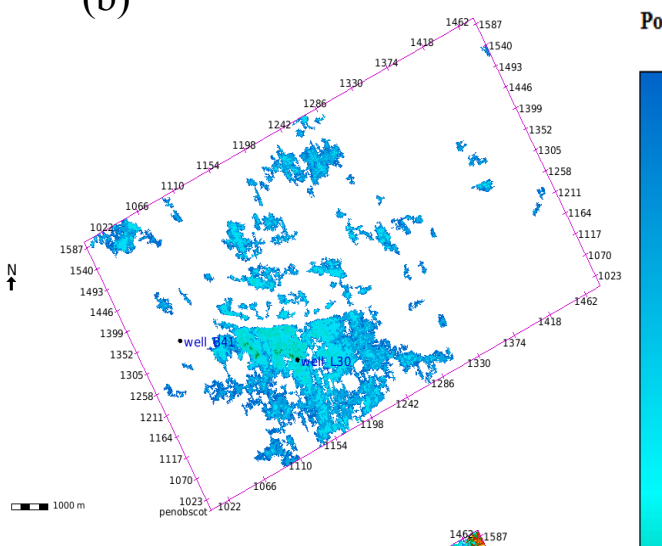

(d)
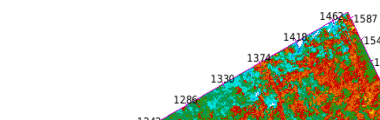


\section{Discussion}

This study applied porosity analysis to the Penobscot seismic data. The methods integrated well log data, inversion data, an AI - porosity crossplot, and calculating thickness, porosity, and pore thickness of the target sand layer.

Gamma Ray (GR) log and Spontaneous Potential (SP) log help to identify sands and carbonates, which is a permeable zone and contains oil and gas. A layer of permeable sand was identified from the GR and SP logs, and tracked through the seismic volume. For rock properties identification, inversion is a good technique for geophysicists. In this study CSSI is used for Penobscot 3D seismic data, and shows the low impedance layer in yellow, which matches the sand layer found by GR and SP logs. Log data helps to calibrate the inversion results, and the phenomenon is strong evidence to indicate the sand layer is a target zone for this study.

The inversion allowed thickness estimates of the highest-porosity (lowest-impedance) portion of this layer, through the seismic volume. But the thickness maps use the thickness unit of TWT, which does not directly present the thickness of the sand layer, so converting to depth is helpful. From five thickness maps, there is low impedance sand in well L-30.

The relationship between AI and porosity was found from the crossplot (Figure 4.4), high porosity is a factor to predict that the sand layer is a good place to store oil or gas. A least-squares fit to the scatter of points in the crossplot was found, calculating the porosity of the sand layer by the linear function. The location of well L-30 has higher porosity than well B-41, therefore L-30 is a better location to explore. 
In order to have more information about the sand layer, the pore thickness was calculated. Porosity and thickness were applied to calculate pore thickness, which directly presents the potential of the sand layer. A greater pore thickness value in well L-30, illustrate that there is more pore space to store oil and gas. If a company wants to do more to verify this reservoir, more wells should be drilled to collect more log data. Because CSSI results are constrained by wells, more known wells in the study area give better inversion results.

\section{Conclusion}

Integrated analysis of the well logs, CSSI inversion result, thickness maps, and the AI - porosity crossplot, provide identification of a potentially commercial zone. In well L-30, there is a sand layer from $2698 \mathrm{~m}$ to $2756 \mathrm{~m}$, and from $2697 \mathrm{~m}$ to $2733 \mathrm{~m}$ in well B-41. These layers have low GR and SP values, which match the low impedance layer from inversion. Based on the inversion result, properties of the whole layer, not only in these two well locations can be calculated: porosity, thickness, and pore thickness of the sand layer. These maps show the values of the whole sand layer, using just two well log datasets. CSSI inversion gives good results in the Penobscot study area. Geophysicists can learn a great deal about a large area by using inversion methods.

Thickness maps, porosity maps, and pore thickness maps give a lot of information, describing in the whole study area. Well L-30 has a thicker sand layer, which has lower acoustic impedance and higher porosity; as a result of this and the high porosity here, it has greater pore thickness than at B-41 or other areas in the survey. 
Interpretations based on this research result can give a good indication of potentially commercial zones. According to the analysis in this research, the sand layer in location well L-30 of the Penobscot area has lower impedance, higher porosity, and greater pore thickness, which indicates well L-30 was the appropriate location for the company to have drilled its first well. Well B-41 was probably drilled to test the limits of good-quality rock, and apparently found lacking. This implies that the reservoir-quality rock is limited to areas found to exhibit acoustic impedance values of $7.9-8.2 \times 10^{6} \mathrm{~kg} / \mathrm{m}^{3 *} \mathrm{~m} / \mathrm{s}$ or $7.9-8.4 \times 10^{6} \mathrm{~kg} / \mathrm{m}^{3 *} \mathrm{~m} / \mathrm{s}$ (for example, see Figures 8.1 and 8.2). There are some similarly valued areas north of the nearby fault, but these are very limited in extent and do not appear to be worthy of further examination by drilling. 


\section{References}

Ahmad, Q., 2013, Mitigation Exploration Risk of Jurassic Reservoir by Seismic Inversion, Penobscot Area, Sable Sub Basin Nova Scotia, Offshore, Canada: Geology \& Geophysics, 2(3).

Campbell, T.J., Richards, F.W.B., Silva, R.L., Wach, G., \& Eliuk, L., 2015, Interpretation of the Penobscot 3D Seismic Volume Using Constrained Sparse Spike Inversion, Sable sub-Basin, Offshore Nova Scotia: Marine and Petroleum Geology, 68, 73-93.

Kidston, A.G., Brown, D.E., Smith, B.M., \& Altheim, B., 2005, The Upper Jurassic Abenaki Formation Offshore Nova Scotia: A seismic and Geologic Perspective (Version 1.0), Canada: Canada Nova Scotia Offshore Petroleum Board.

Dewan, J.T., 1983, Essentials of Modern Open-Hole Log Interpretation: PennWell Publishing Company.

Sayers, J. E., 2013, Enhancement of the Geological Features of the Scotian Basin by the Application of Spectral inversion, Offshore Nova Scotia: M.S. thesis, University of Houston.

Veeken, P.C.H., \& Silva, M.D., 2004, Seismic Inversion Methods and some of Their Constraints: First Break, 22, no. 6, V47-V70. 
Wang, Q., \& Lu, Z., 2011, Application of Constrained Sparse Spike Inversion in Reservoir Predication: A Case of Study of Oriente Basin in South America: Global Geology, 14 (2), 87-93.

Wang, X., Wu, S., Xu, N., \& Zhang, G., 2006, Estimation of Gas Hydrate Saturation Using Constrained Sparse Spike Inversion: Case Study from the Northern South China Sea: Terrestrial, Atmospheric and Oceanic Sciences, 17, no. 4, V799-V813. 


\section{Appendix I : Thickness Time Map}

We obtained five relative thickness maps in time units for five different impedance ranges. The lower limit of the impedance intervals of all five maps is the lowest impedance value for the target layer, but the upper limit numbers are different for each map.

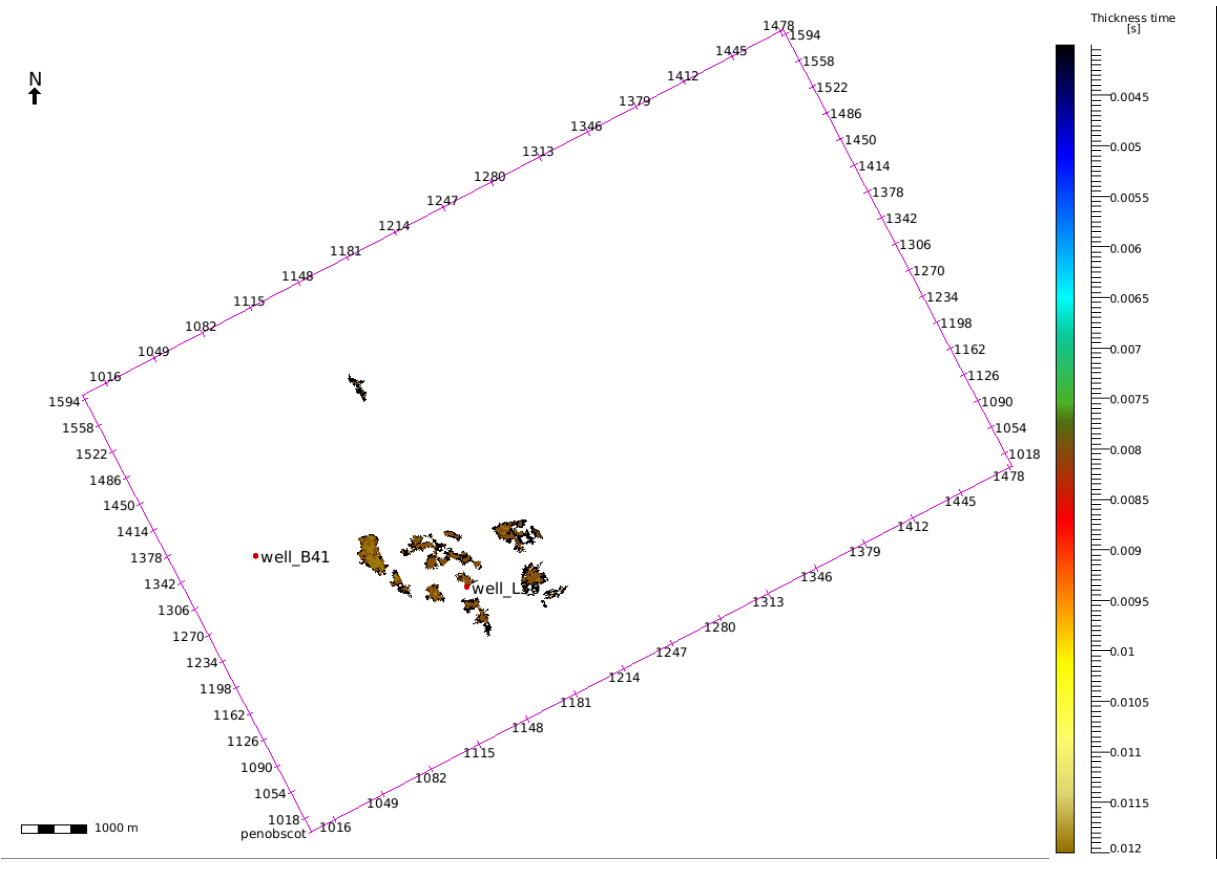

Figure 8.1. The thickness map (TWT unit) of impedance between $7.9 \times 10^{6} \mathrm{~kg} / \mathrm{m}^{3 *} \mathrm{~m} / \mathrm{s}$ to $8.2 \times 10^{6} \mathrm{~kg} / \mathrm{m}^{3 *} \mathrm{~m} / \mathrm{s}$. These two well locations are shown as red points. 


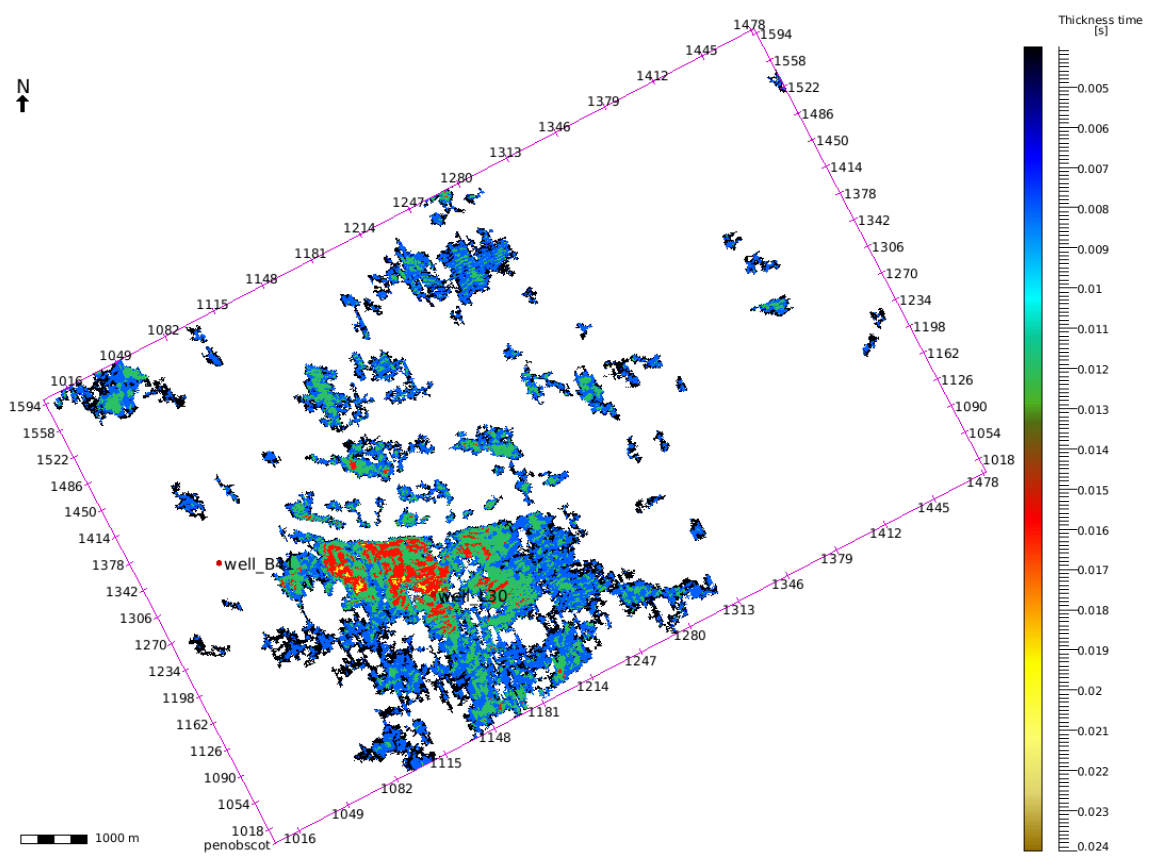

Figure 8.2. The thickness map (TWT unit) of impedance between $7.9 \times 10^{6} \mathrm{~kg} / \mathrm{m}^{3 *} \mathrm{~m} / \mathrm{s}$ to $8.4 \times 10^{6} \mathrm{~kg} / \mathrm{m}^{3 *} \mathrm{~m} / \mathrm{s}$. These two well locations are shown as red points.

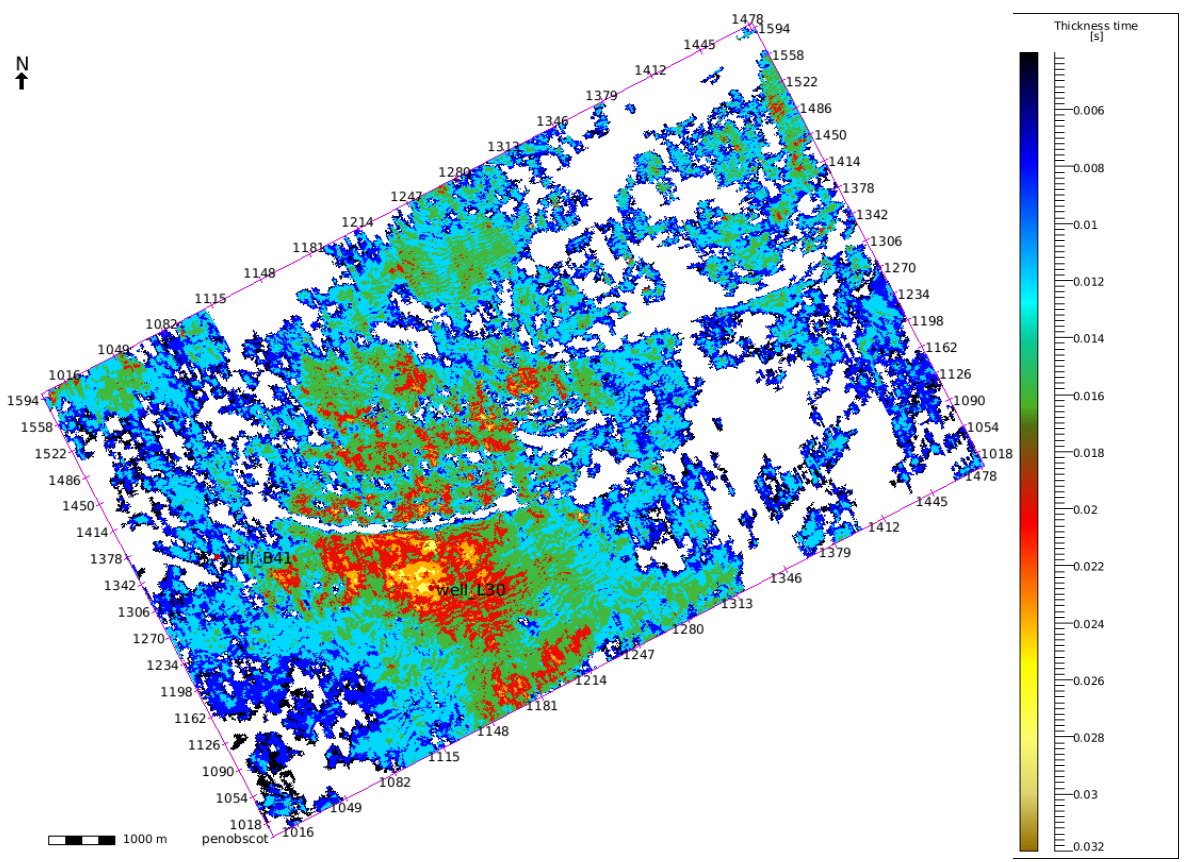

Figure 8.3. The thickness map (TWT unit) of impedance between $7.9 \times 10^{6} \mathrm{~kg} / \mathrm{m}^{3 *} \mathrm{~m} / \mathrm{s}$ to $8.6 \times 10^{6} \mathrm{~kg} / \mathrm{m}^{3 *} \mathrm{~m} / \mathrm{s}$. These two well locations are shown as red points. 


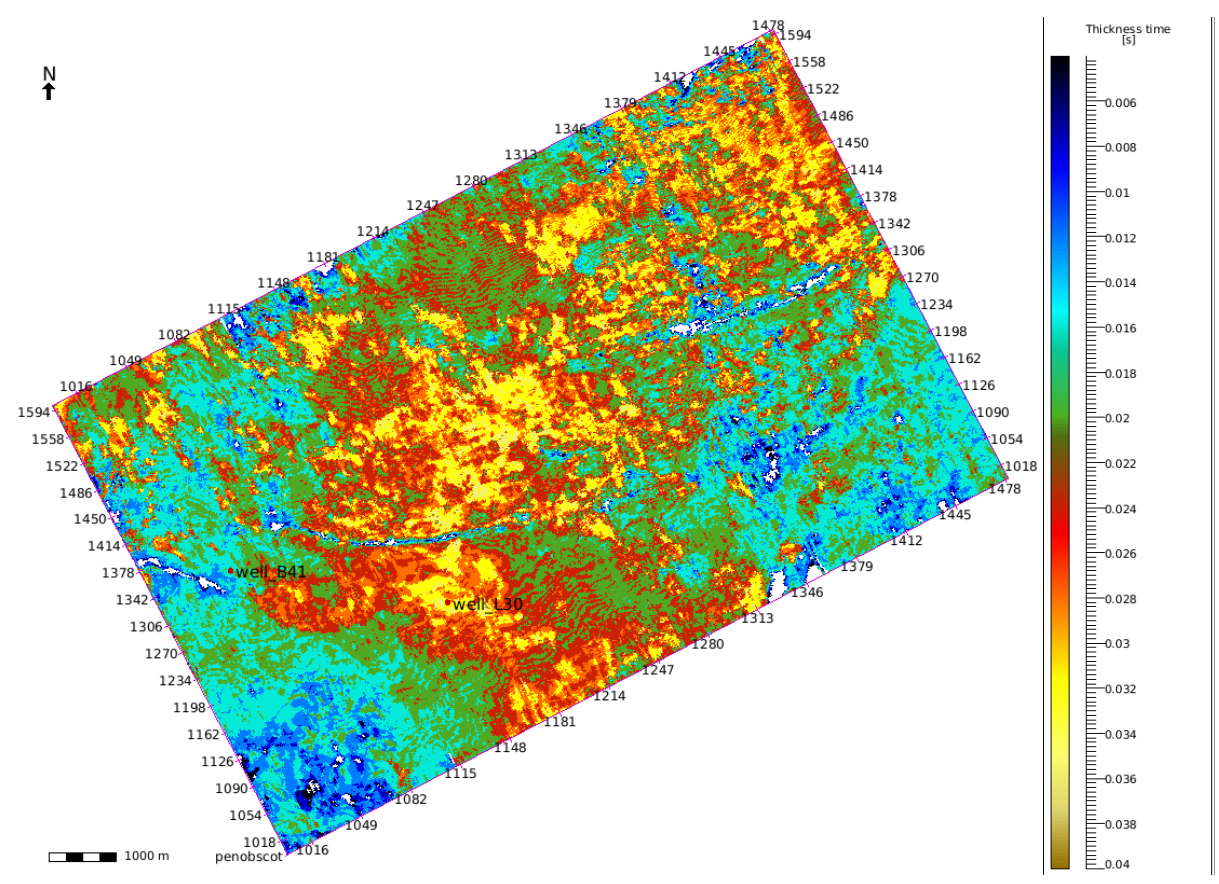

Figure 8.4. The thickness map (TWT unit) of impedance between $7.9 \times 10^{6} \mathrm{~kg} / \mathrm{m}^{3 *} \mathrm{~m} / \mathrm{s}$ to $8.8 \times 10^{6} \mathrm{~kg} / \mathrm{m}^{3 *} \mathrm{~m} / \mathrm{s}$. These two well locations are shown as red points.

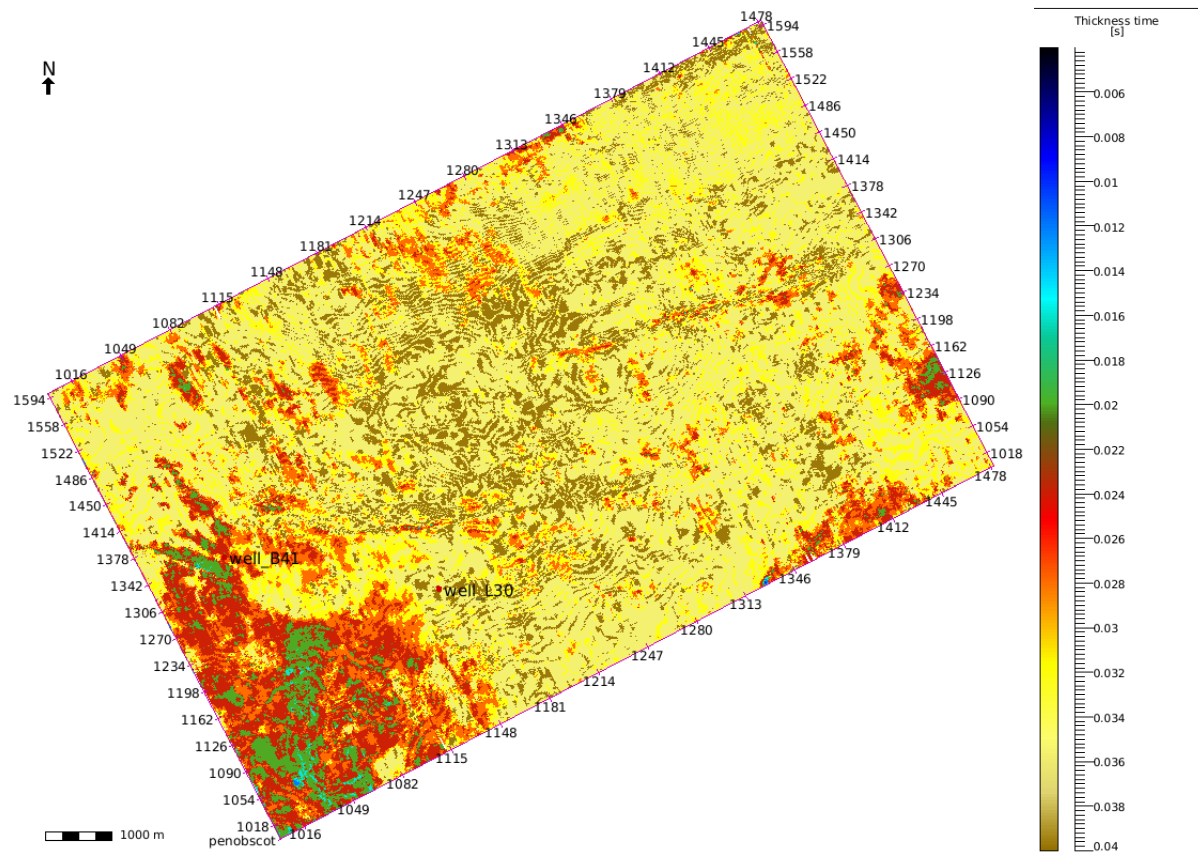

Figure 8.5. The thickness map (TWT unit) of impedance between $7.9 \times 10^{6} \mathrm{~kg} / \mathrm{m}^{3 *} \mathrm{~m} / \mathrm{s}$ to $9.0 \times 10^{6} \mathrm{~kg} / \mathrm{m}^{3 *} \mathrm{~m} / \mathrm{s}$. These two well locations are shown as red points. 